Portland State University

PDXScholar

\title{
Assessing Transit Fare Equity in Utah Using a Geographic Information System
}

\author{
Steven Farber \\ University of Utah \\ Keith Batholomew \\ University of Utah \\ Xiao Li \\ University of Utah \\ Antonio Paez \\ McMaster University \\ Khandker M. Nurul Habib \\ University of Toronto
}

Follow this and additional works at: https://pdxscholar.library.pdx.edu/trec_reports

Part of the Transportation Commons, Urban Studies Commons, and the Urban Studies and Planning Commons

Let us know how access to this document benefits you.

\section{Recommended Citation}

Farber, Steven, Keith Bartholomew, Xiao Li, Antonio Paez, and Khandkher M. Nurul Habib. Assessing Transit Fare Equity in Utah Using a Geographic Information System. NITC-RR-540. Portland, OR: Transportation Research and Education Center (TREC), 2014. https://doi.org/10.15760/trec.87

This Report is brought to you for free and open access. It has been accepted for inclusion in TREC Final Reports by an authorized administrator of PDXScholar. Please contact us if we can make this document more accessible: pdxscholar@pdx.edu. 


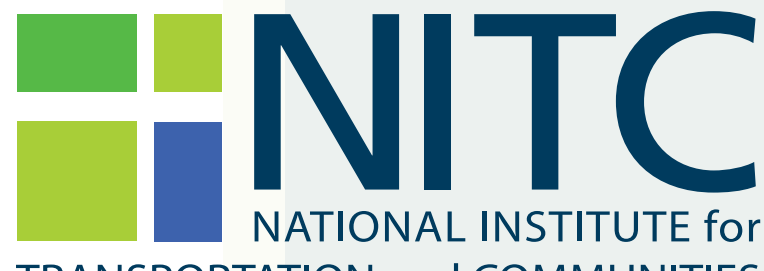

TRANSPORTATION and COMMUNITIES

\section{FINAL REPORT}

\section{Assessing Transit Fare Equity in Utah Using a Geographic Information System}

NITC-RR-540 July 2014

NITC is the U.S. Department of Transportation's national university transportation center for livable communities.

\#": TREC 


\title{
ASSESSING TRANSIT FARE EQUITY IN UTAH USING A GEOGRAPHIC INFORMATION SYSTEM
}

\author{
Final Report \\ NITC-RR-540 \\ by
}

Steven Farber, Keith Bartholomew, Xiao Li - University of Utah Antonio Paez - McMaster University

Khandker M. Nurul Habib - University of Toronto

for

National Institute for Transportation and Communities (NITC)

P.O. Box 751

Portland, OR 97207

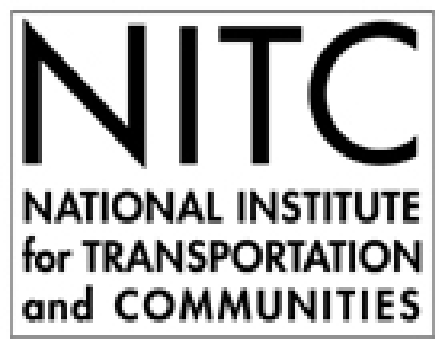

July 2014 



\begin{tabular}{|c|c|c|c|c|c|}
\hline \multicolumn{6}{|c|}{ Technical Report Documentation Page } \\
\hline $\begin{array}{l}\text { 1. Report No. } \\
\text { NITC-RR-540 }\end{array}$ & \multicolumn{3}{|l|}{ 2. Government Accession No. } & \multicolumn{2}{|c|}{ 3. Recipient's Catalog No. } \\
\hline \multicolumn{4}{|c|}{$\begin{array}{l}\text { 4. Title and Subtitle } \\
\text { ASSESSING TRANSIT FARE EQUITY IN UTAH USING A GEOGRAPHIC INFORMATION } \\
\text { SYSTEM }\end{array}$} & \multicolumn{2}{|c|}{$\begin{array}{l}\text { 5. Report Date } \\
\text { July } 2014\end{array}$} \\
\hline \multicolumn{4}{|c|}{$\begin{array}{l}\text { 7. Author(s) } \\
\text { Steven Farber, Keith Bartholomew, Xiao Li - University of Utah, Antonio Paez - McMaster } \\
\text { University, Khandker M. Nurul Habib - University of Toronto }\end{array}$} & \multicolumn{2}{|c|}{ 8. Performing Organization Report No. } \\
\hline \multicolumn{4}{|c|}{$\begin{array}{l}\text { 9. Performing Organization Name and Address } \\
\text { Steven Farber } \\
\text { Department of Geography } \\
\text { University of Utah } \\
\text { 260 S Central Campus Dr Rm } 270 \\
\text { Salt Lake City, UT } 84112-9155\end{array}$} & \multicolumn{2}{|c|}{ 11. Contract or Grant No. } \\
\hline \multicolumn{4}{|l|}{$\begin{array}{l}\text { 12. Sponsoring Agency Name and Address } \\
\text { Oregon Transportation Research } \\
\text { and Education Consortium (OTREC) } \\
\text { P.O. Box } 751 \\
\text { Portland, Oregon } 97207\end{array}$} & \multicolumn{2}{|c|}{ 14. Sponsoring Agency Code } \\
\hline \multicolumn{6}{|l|}{ 15. Supplementary Notes } \\
\hline \multicolumn{6}{|c|}{$\begin{array}{l}\text { 16. Abstract } \\
\text { The goal of this study is to develop and apply a new method for assessing social equity impacts of } \\
\text { distance-based public transit fares. Shifting to a distance-based fare structure can disproportionately favor } \\
\text { or penalize different subgroups of a population based on variations in settlement patterns, travel needs, } \\
\text { and most importantly, transit use. According to federal law, such disparities must be evaluated by the } \\
\text { transit agency, but the area-based techniques identified by the Federal Transit Authority for assessing } \\
\text { discrimination fail to account for disparities in distances travelled by transit users. This means that transit } \\
\text { agencies currently lack guidelines for assessing the social equity impacts of replacing flat fare with } \\
\text { distance-based fare structures. Our solution is to incorporate a joint ordinal/continuous model of trip } \\
\text { generation and distance travelled into a GIS Decision Support System. The system enables a transit } \\
\text { planner to visualize and compare distance travelled and transit-cost maps for different population profiles } \\
\text { and fare structures. We apply the method to a case study in the Wasatch Front, Utah, where the Utah } \\
\text { Transit Authority is exploring a switch to a distance-based fare structure. The analysis reveals that overall } \\
\text { distance-based fares benefit low-income, elderly, and non-white populations. However, the effect is } \\
\text { geographically uneven, and may be negative for members of these groups living on the urban fringe. }\end{array}$} \\
\hline $\begin{array}{l}\text { 17. Key Words } \\
\text { Distance based fares, social equity, joint } \\
\text { model, distance traveled model }\end{array}$ & liscrete model, trip generation & & $\begin{array}{l}\text { ibution } \\
\text { rictions } \\
\text { trec.us }\end{array}$ & $\begin{array}{ll}\text { ement } \\
\text { opies av }\end{array}$ & \\
\hline $\begin{array}{l}\text { 19. Security Classification (of this report) } \\
\text { Unclassified }\end{array}$ & $\begin{array}{l}\text { 20. Security Classification (of tl } \\
\text { Unclassified }\end{array}$ & & & $\begin{array}{r}\text { of Pages } \\
55\end{array}$ & 22. Price \\
\hline
\end{tabular}




\section{ACKNOWLEDGEMENTS}

This project was funded by National Institute for Transportation and Communities (NITC) and administered by the Oregon Transportation Research and Education Consortium (OTREC). The authors thank Max Backlund, the anonymous reviewers at the TRB for their thoughtful suggestions, and our partners at the Utah Transit Authority.

\section{DISCLAIMER}

The contents of this report reflect the views of the authors, who are solely responsible for the facts and the accuracy of the material and information presented herein. This document is disseminated under the sponsorship of the U.S. Department of Transportation University Transportation Centers Program in the interest of information exchange. The U.S. Government assumes no liability for the contents or use thereof. The contents do not necessarily reflect the

official views of the U.S. Government. This report does not constitute a standard, specification, or regulation. 


\section{TABLE OF CONTENTS}

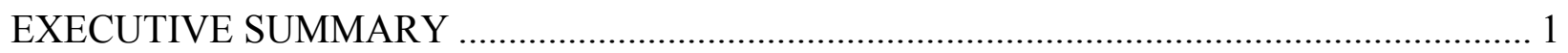

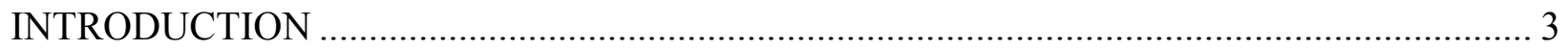

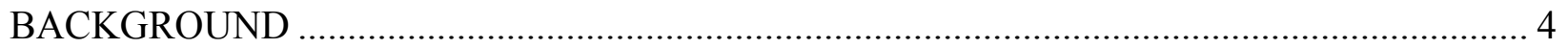

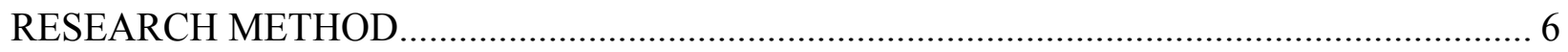

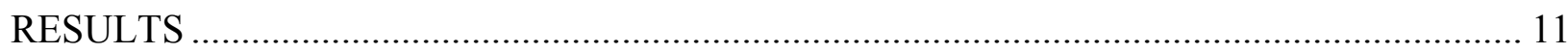

CONCLUSIONS

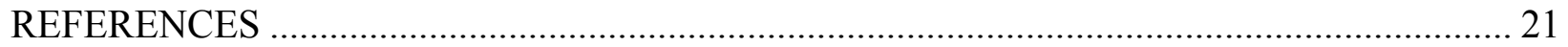

\section{APPENDICES}

APPENDIX A: FARE EQUITY ANALYZER TOOLBOX ............................. 25

\section{LIST OF TABLES}

Table 3.1: Transit Ridership, Trip Generations, and Distance Travelled for Select Personal and Household Characteristics ........................................................................................... 7-8

Table 3.2: Distance to CBD and Transit Facilities Amongst Transit Riders and Non-Riders ....... 9 Table 4.1: Results of the Joint Ordinal/Continuous Model for Public Transit Trip Generation and

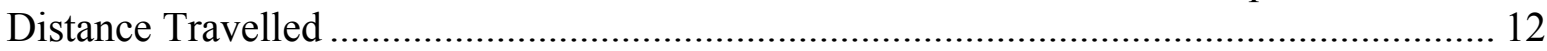

Table 4.2: Average Fare Change for Different Population Groups ................................................ 16

\section{LIST OF FIGURES}

Figure 4.1: Expected Distances Travelled by Public Transit for Socioeconomic Profiles A)

Reference Group, B) Low Income and Ed, C) Low Income/Elderly D) Non-White.........14

Figure 4.2: Expected Change in Fare for Travelers Taking Two Transit Trips in a Day A)

Reference Group, B) Low Income+Education, C) Low Income/Elderly D) Non-White..... 17

Table 4.3: Fare Increases for Non-White and Hispanic Travelers Overlaid with Non-White and

Hispanic Census Tracts ............................................................................................ 18 


\section{EXECUTIVE SUMMARY}

The goal of this study is to develop and apply a new method for assessing social equity impacts of distance-based public transit fares. Shifting to a distance-based fare structure can disproportionately favor or penalize different subgroups of a population based on variations in settlement patterns, travel needs, and most importantly, transit use. According to federal law, such disparities must be evaluated by the transit agency, but the area-based techniques identified by the Federal Transit Authority for assessing discrimination fail to account for disparities in distances travelled by transit users. This means that transit agencies currently lack guidelines for assessing the social equity impacts of replacing flat fare with distance-based fare structures.

Our solution is to incorporate a joint ordinal-continuous model of trip generation and distance travelled into a GIS Decision Support System. The system enables a transit planner to visualize and compare estimated distances travelled and transit-cost maps for different population profiles and fare structures. We apply the method to a case study in the Wasatch Front, Utah, where the Utah Transit Authority is exploring a switch to a distance-based fare structure. The analysis reveals that overall distance-based fares benefit low-income, elderly, and non-white populations. However, the effect is geographically uneven, and may be negative for members of these groups living on the urban fringe.

The research discusses a potential conflict between policies designed to promote equity and those intended to increase discretionary ridership. For example, increasing fares for longdistance discretionary riders travelling from suburban light-rail stations to the central business district may have a negative impact on ridership, despite being economically more efficient through cost-recapturing. At the same time, reducing fares for short-distance trips that are currently too expensive compared to private automobile travel may attract new riders. A full cost-benefit analysis sensitive to heterogeneous price elasticity is recommended for future research.

It is also noted that the research findings are dependent on the current spatial distributions of population segments and travel patterns. The equity benefits of distance-based fares are primarily derived from residential clustering of low-income and minority groups in more compact urban areas near the center of the city. Demographic trends, such as inner-city gentrification and suburban aging-in-place, may impose increased travel demands on lowincome and elderly riders, nullifying future equity gains made by a transition to distance-based fares. 


\section{INTRODUCTION}

Transport policy is inherently spatial. In the particular case of public transportation, building new transit infrastructure, changing the level of service, or modifying transit fares differentially impacts the spatial distributions of costs and benefits associated with this form of mobility. Despite its importance, few tools exist to aid researchers and planners in analyzing social equity, the fairness of cost-benefit distributions over space and across different population groups. Given the increasing importance placed on sustainability principles, it becomes salient to the transportation sector to balance environmental and economic concerns with those that are social, such as justice and equity. Without the proper tools, social equity analyses have been systematically underrepresented in transportation planning research and practice, or at least performed in an inconsistent, ad hoc manner across the country (Deka, 2004).

This research aims to address this gap by developing a Geographic Information Systembased Decision Support System (GIS-DSS) for evaluating the social equity impacts of transit fare policy. GIS-DSSs assist users with evaluating the costs and benefits of hypothetical solutions to inherently spatial problems, and they are recommended by the Federal Transit Administration for analyzing the equity impacts of proposed changes in transit route and fare structures (Federal Transit Administration, 2012). The work has been performed in consultation with the Utah Transit Authority (UTA), a transit agency currently in the midst of reforming its transit fare strategy; the agency is considering a shift from a flat-rate fare to a distance-based fare structure. The UTA is a large, state-authorized transit operator in the United States. It services a population of 1.8 million people with a fleet of buses, vanpools, and light- and commuter-rail locomotives. Similar to many transit agencies in the U.S., the UTA currently charges a "localservice" flat-rate fare for one- and two-way trips irrespective of distance travelled on the transit system. Following a steep decline in UTA revenues during the recent economic downturn, UTA is considering a distance-based fare structure in an effort to generate higher levels of ridership (for shorter-distance travelers) and greater levels of fare-box revenue overall.

This research aims to improve our understanding of transit fares and social equity. We evaluate the equity implications of UTA moving from a flat-rate fare to a distance-based fare strategy through the development of a "Fare Equity Analyzer GIS" (FEAGIS), a spatial database tool that meets the strategic planning needs of the UTA while providing a platform for social equity research. The GIS enables us to investigate the fairness in distributions of transit fare costs across multiple geographic scales and socioeconomic dimensions. To achieve this goal, we estimate a state-of-the-art spatial econometric joint model of trip generation and distance travelled. The model is then incorporated into a GIS so that fare strategies may be assessed for equity concerns. 


\section{BACKGROUND}

Research pertaining to socially sustainable transportation has evaluated the role of transportation in social exclusion, quality of life, and social equity (alternatively justice or fairness) at local and regional scales (Boschmann et al., 2008; Litman et al., 2011). The notion of social equity in transportation is summarized by Sanchez et al. (2007) as the distribution of "benefits and burdens from transportation projects equally across all income levels and communities" (p. 8). It follows that socially equitable transportation is concerned with fairness in the distribution of transport investments, internal and external costs, and benefits (Garrett et al., 1999; Martens, 2009). The evaluation of costs may pertain to environmental justice (Lucas, 2004); public health externalities (Frumkin, 2002); fiduciary expenses such as tax burdens (Wachs, 2003;King, 2011); tolls and congestion pricing (Giuliano, 1994;Plotnik et al., 2011); and transit prices and fare structures (Cervero, 1990; Debet et al., 2011; Fan et al., 2011).

The links between transportation and social justice have deep historic and political roots. In the United States, for instance, this history includes landmark Supreme Court decisions, bus boycotts, Freedom Riders, and the passage of federal legislation (e.g., Sanchez et al., 2007; Bullard et al., 2004)), including the Civil Rights Act of 1964. Title VI of that act prohibits federally funded transit providers such as the UTA from administering programs in ways that would subject individuals to discrimination based on their race, color or national origin. President Clinton's 1994 Environmental Justice Executive Order similarly bars transit agencies from acting in ways that would have disproportionately high and adverse effects on low-income populations (Federal Transit Administration, 2012).

Equity can be examined from a variety of perspectives. Building on Litman's (2002) theoretical structure, Bullard et al. (2004) identifies three types of equity: horizontal equity, which focuses on fairness between those of comparable wealth and ability; vertical equity with regard to income and social class, which looks at cost-benefit distributions between social and economic groups; and vertical equity with regard to mobility need and ability, which assesses "how well an individual's transportation needs are met compared with other in their community" (p. 26). Taylor (2004) refines these concepts further, creating a three-by-three matrix that assesses three units of analysis (geographic, group and individual) against three types of equity (market, opportunity and outcome).

Various examinations of equity have been reported in the international literature, with the objective of assessing mainly vertical equity by comparing service availability to needs. In Melbourne, Australia, Currie (2010) combined information about the distribution of transit stops and number of trips per week to create a supply-side service index. On the other hand, deprivation and a transport index (constructed using variables such as number of adults without cars and number of persons with disabilities) were used to measure social transport needs. The approach developed by Currie is useful to identify need gaps, that is, areas with high needs and limited or non-existent transit services, which in the case of Melbourne were found to be mostly in the periphery of the city. Bocarejo and Oviedo ( 2012) also adopted a geographical perspective for their study of a bus rapid transit line in Bogotá, Colombia. These authors considered the percentage of time and income that travelers needed to spend to reach employment locations using the system. Whereas Currie's approach considered only the ability to enter the transit system, Bocarejo and Oviedo were also concerned with the ability to reach destinations. The results of the analysis for Bogotá indicate that purchasing power and location can combine to 
influence the redistributive effects of a project. Furthermore, the case study illustrates a situation where fare policy can have a greater equity impact than the expansion of the network.

In the U.S., the mandate to comply with Title VI has also prompted studies of equity. For instance, Nuworsoo, Golub and Deakin ( 2009) analyzed a series of fare proposals for AlamedaContra Costa Transit District in California, using disaggregated analysis of fares that considered the attributes of trip-makers (e.g., income, age, race), as well as their travel behavior. More recently, Hickey et al. (2010) argued for the use of quantitative approaches to assess equity, and illustrated the use of travel statistics and statistical methods for evaluating the impact of restructuring transit fares. A notable limitation noted for New York City Transit is the assumption that "elasticities in fare class and cross-elasticities between fare classes are independent of geography and demographics" (p. 82). The adequacy of this assumption is suspect. In the specific case of the U.S., there is substantial evidence of spatial segregation along socio-economic and demographic dimensions (e.g., Kucheva, 2013; Massey et al., 2000). Not surprisingly, this has an effect on transport equity. Haas et al. ( 2006), for instance, documented the tradeoffs facing U.S. households in metropolitan areas in terms of housing and transportation costs. The average percentage of income spent in transportation by low-income households $(<\$ 20 \mathrm{~K})$ was a staggering $56 \%$ in 2000 , at the end of an historic economic growth period, and before the economic recessions of the next decade. By contrast, the average percentage of income spent in transportation was only $18 \%, 13 \%$ and $8 \%$ for the top three income classes ( $\$ 50 \mathrm{~K}$ to $\$ 75 \mathrm{~K}, \$ 75 \mathrm{~K}$ to $\$ 100 \mathrm{~K}$, and $\$ 100 \mathrm{~K}$ to $\$ 250 \mathrm{~K}$, respectively). In this fashion, while transit systems may not intentionally discriminate against low-income and minority populations, flat-rate fare prices may, nevertheless, have disparate impacts on low-income and minority households by virtue of the higher rates of transit usage and the tendency for shorter trips exhibited by members of these households, compared to members of the general population (Sanchez et al., 2007; Cervero, 1982). These differences in usage can lead to situations where minority and low-income riders are effectively subsidizing other riders who use transit only for commute purposes and/or travel longer distances.

Of several fare structures, the literature on distance-based fares is not extensive, since much of the material seems to focus rather on optimizing fare structures for enhancing revenues (Li et al., 2012; Daskin et al., 1985; Lam et al., 2000; Tsai et al., 2008; Joregensen et al., 2007). However, of the various schemes analyzed by Nuworsoo, Golub and Deakin (2009) for Alameda-Contra Costa Transit District patrons, flat fares were found to most negatively impact vulnerable populations (youth, low-income, and minority travelers) due to their more frequent use of transit and transfer patterns. This finding is consistent with earlier works by Ballou \& Mohan (1981), Cervero (1982), and Deakin and Harvey (1996). Implementing a distance-based fare system presents the UTA with the opportunity to take affirmative steps to alleviate disparate effects. The case for distance-based fares, however, is not clear cut. Distance-based fares might exacerbate concerns over spatial mismatch, a situation arising from large spatial separations between low-income and minority households and suitable locations of employment or other locations of participation (Sanchez et al., 2007). To the extent that spatial mismatch exists, distance-based fares may result in increased out-of-pocket travel expenses for those low-income households engaged in long-distance travel routines. Furthermore, increasing fares for longdistance transit riders may result in increased use of less sustainable modes of transportation, namely the automobile. Such a change could lead to increased greenhouse gas emissions, lower air-quality, more traffic accidents and increased traffic congestion. Spatial disparities in the social benefits of distance-based fares must therefore be accurately calculated in order to 
facilitate a comparison with economic and environmental costs. The system presented in this paper aims to facilitate the analysis of equity based on detailed analysis of socioeconomic, demographic and geographical factors.

\section{RESEARCH METHOD}

\section{DATA}

The research primarily relies on data from the Utah Household Travel Survey (UHTS) conducted in the spring of 2012. The one-day trip survey recorded 101,404 trips taken by 27,046 individuals living in 9,155 households. The survey, being partially funded by metropolitan planning organizations along the Wasatch Front, oversampled the urbanized regions in which UTA operates. This provides a spatially dense sample of 6,238 households considered to be within the operating district of the transit authority.

The UHTS collected information about individual trips, the trip-makers and households. Descriptive characteristics of the dataset can be found in Table 1. The table indicates social disparities in transit trip generation and distance travelled. Note that the table only includes factors that directly relate to social equity concerns in the Wasatch Front, but additional control variables are used in the multivariate model below. We present the percentage of respondents in each factor level that reported a transit trip, and the mean trip generation rate and mean total distance travelled among transit riders.

The summary transit ridership statistics tell a consistent story of higher ridership but shorter distances travelled among individuals of lower socioeconomic status. Interestingly, contrasting the pattern seen for trip distances, there is very little variation in numbers of trips generated per transit rider. Looking at socioeconomic status, compared to individuals in highincome households, individuals in households earning less than $\$ 35,000$ per year were more than twice as likely to ride transit, but had average distances of nearly half the length. Hispanics and non-white respondents are $70 \%$ more likely to ride transit in comparison to non-Hispanics and whites, but whites travelled about $45 \%$ greater distances on transit than their non-white counterparts. In terms of employment status, students who are employed for more than 25 hours per week have the highest penetration rates of transit use, but fully employed transit riders travelled 40-65\% longer distances compared to others. In all of these cases, distance-based fares would seem to be favorable to lower socioeconomic groups given their increased uptake of transit ridership (in terms of mode share) but decreased use of long-distance services.

The same benefit of distance-based fares can by posited to exist along other socioeconomic dimensions. Those without driver's licenses were about six times more likely to ride transit than licensed respondents, but licensed transit riders traveled 80\% longer distances. Of those living in carless households, $27.3 \%$ reported using transit, taking 2.26 transit trips per day with a mean total distance travelled of only 11.94 miles per day. This is all in comparison to $1.87 \%$ of two-car households, averaging 1.89 trips per day but travelling 38.14 miles. Related to car ownership are the factors of neighborhood and residence types. Those living in apartment buildings and in mixed-use urban areas reported much higher rates of transit use, but with much shorter distances travelled. 
TABLE 3.1 Transit Ridership, Trip Generations, and Distance Travelled for Select Personal and Household Characteristics

\begin{tabular}{|c|c|c|c|}
\hline & $\begin{array}{l}\text { Ridership } \\
\text { Percentage }\end{array}$ & Trips & $\begin{array}{l}\text { Distance Travelled } \\
\text { (miles) }\end{array}$ \\
\hline \multicolumn{4}{|l|}{ Household Income $<0.014,0.002>$} \\
\hline No Answer & 1.91 & 1.73 & 20.09 \\
\hline Under $\$ 35,000$ & 5.17 & 1.94 & 13.25 \\
\hline$\$ 35,000-\$ 49,999$ & 2.94 & 1.88 & 19.14 \\
\hline$\$ 50,000-\$ 99,999$ & 2.24 & 1.85 & 20.56 \\
\hline$\$ 100,000$ or more & 2.17 & 1.86 & 24.51 \\
\hline \multicolumn{4}{|l|}{ Hispanic $<0.038,0.348>$} \\
\hline Yes & 4.38 & 1.89 & 17.39 \\
\hline No & 2.60 & 1.88 & 19.60 \\
\hline Prefer not to answer & 3.02 & 1.64 & 5.34 \\
\hline \multicolumn{4}{|l|}{ Race $<0.000,0.018>$} \\
\hline White or Caucasian & 2.50 & 1.89 & 19.93 \\
\hline All other & 4.61 & 1.77 & 14.25 \\
\hline \multicolumn{4}{|l|}{ Age $<0.110,0.944>$} \\
\hline 18-24 years old & 6.87 & 1.82 & 17.47 \\
\hline 25-34 years old & 4.07 & 1.88 & 17.51 \\
\hline $35-44$ years old & 3.37 & 1.84 & 24.19 \\
\hline 45-54 years old & 3.49 & 1.87 & 19.73 \\
\hline 55-64 years old & 3.13 & 1.88 & 17.82 \\
\hline$>65$ years old & 1.59 & 2.08 & 13.91 \\
\hline \multicolumn{4}{|l|}{ Employment $<0.000,0.000>$} \\
\hline Employed full-time & 4.58 & 1.84 & 22.43 \\
\hline Employed part-time & 3.05 & 1.84 & 13.61 \\
\hline Student, not employed or employed less than $25 \mathrm{hrs} /$ week & 6.88 & 1.76 & 15.96 \\
\hline Student, employed 25+ hrs/week & 10.79 & 1.91 & 14.61 \\
\hline All Other & 1.36 & 2.00 & 13.88 \\
\hline \multicolumn{4}{|l|}{ Education $<0.017,0.005>$} \\
\hline High school or less & 3.73 & 1.85 & 13.08 \\
\hline Some college/vocational/associates & 3.40 & 1.87 & 18.56 \\
\hline Bachelors & 2.90 & 1.80 & 19.34 \\
\hline Grad/post grad & 5.26 & 1.95 & 21.88 \\
\hline \multicolumn{4}{|l|}{ Licensed $<0.000,0.000>$} \\
\hline Yes & 3.14 & 1.86 & 20.39 \\
\hline No & 13.67 & 1.96 & 11.34 \\
\hline \multicolumn{4}{|l|}{ Limited Mobility <0.012,0.290> } \\
\hline Yes & 7.05 & 2.09 & 14.99 \\
\hline No & 3.51 & 1.86 & 19.16 \\
\hline
\end{tabular}


Prefer not to answer

Number of vehicles $<0.000,0.000>$

Zero vehicle household

1 vehicle household

2 vehicle household

$3+$ vehicle household

Home Ownership <0.000,0.000>

Rent

Own

Other

Number of years (Residence) $<0.158,0.000>$

less than 1 year

1 to 5 years

more than 5 years

Place Type (Self-reported) <0.000,0.000>

City, downtown with a mix of offices, apartments and shops

City, residential neighborhood

Suburban neighborhood, with a mix of houses, shops and businesses

Suburban neighborhood, with houses only

Other

Residence Type <0.000,0.000>

Single-family house (detached house)

$2.17 \quad 1.88$

$6.17 \quad 1.92$

3.34

2.00

2.26

7.42

$5.40 \quad 1.78$

14.04

$1.87 \quad 1.89$

23.70

$1.99 \quad 1.81$

23.21

$5.56 \quad 1.86$

11.66

$2.17 \quad 1.87$

22.77

$0.77 \quad 2.00$

17.61

$4.44 \quad 1.97$

16.23

$2.58 \quad 1.88$

19.21

$\begin{array}{lll}2.42 & 1.83 & 19.96\end{array}$

$7.44 \quad 1.72$

7.41

$2.82 \quad 1.94$

13.72

$3.15 \quad 1.91$

22.28

2.09

1.83

22.95

$1.61 \quad 1.78$

34.41

Building with 4 or more apartments or condos

1.92

1.74

Ridership Percentage is the percentage of respondents that reported a public transit trip. Trips is the average number of trips reported amongst those who took transit. Distance Travelled is the average number of miles travelled on transit by those who took transit. ANOVA results in format $\langle\boldsymbol{A}, \boldsymbol{B}\rangle$ where $\mathbf{A}$ is the $\mathrm{p}$-value of the F-test associated with ridership and $\mathbf{B}$, is the p-value of the F-test associated with distance travelled.

Next, we turn to investigate locational factors that may influence transit use: Distance to the central business district (CBD) and distance to the nearest bus stop, Trax (light-rail) stop, and Front Runner (commuter-rail) station. Table 2 shows two clear patterns. First, respondents with residences closer to the $\mathrm{CBD}$ and various public transit facilities are more likely to ride transit. Second, amongst transit riders, living farther away from the CBD and transit facilities is associated with longer distances travelled.

The descriptive analysis of transit ridership and distance travelled reveals a common pattern across a multitude of socioeconomic factors. It is important to realize that these descriptive results are uncontrolled; effects of one factor, like income, may be correlated with another, such as employment status. For this reason, a multivariate approach to modeling trip generations and distances travelled is applied next. This will help determine the independent impact of each dimension explored above. 
TABLE 3.2: Distance to CBD and Transit Facilities Amongst Transit Riders and Non-Riders

\begin{tabular}{lrrrr} 
& CBD & Bus Stop & Trax Stop & FrontRunner \\
\hline Mean Distance for Non-Transit Riders & 21.06 & 0.50 & 13.73 & 15.97 \\
Mean Distance for Transit Riders & 15.47 & 0.37 & 9.57 & 10.75 \\
Ratio (Row 1/Row 2) & 1.36 & 1.47 & 1.43 & 1.49 \\
Correlation with Distance Travelled & 0.46 & 0.22 & 0.39 & 0.24 \\
\hline
\end{tabular}

\section{JOINT ORDINAL/CONTINUOUS MODEL}

In this section we put forward the derivation of an ordinal/continuous model that will be used to simultaneously estimate the joint decision of how many transit trips to take (discrete ordered), and how far to travel by transit in a day (continuous). Probability functions for each dependent variable and a correlation structure between the random components affecting each decision process will be accounted for. This procedure controls for the selection bias associated with only observing transit travel distance for those respondents that selected to travel by transit for one or more trips on the survey day. Ignoring the ordinal selection process is likely to result in biased estimates of regression coefficients in the continuous, distance-travelled function (Paez et al., 2008).

In order to derive the model, let us begin by considering that an individual incurs some cost in deciding to make a transit trip. Defining cost as a generalized negative utility sensitive to sociodemographic characteristics of individuals, we can specify a function as:

$$
C^{*}=\beta x+\varepsilon
$$

where, $C^{*}$ indicates total disutility of trips generated, $x$ is the vector of explanatory variables, $\beta$ is the vector of corresponding coefficients, and $\varepsilon$ is the unobserved error term. Considering the number of transit trips to make as an ordered decision, it is possible to define the probability of taking successive numbers of trips, $T$, based on generalized cost as:

$$
\begin{array}{llll}
T=3+ & \text { if } & C^{*} \leq \mu_{3} & \& \operatorname{Pr}(T=3+)=\Phi\left(\mu_{3}-\beta x\right) \\
T=2 & \text { if } & \mu_{3}<C^{*} \leq \mu_{2} & \& \operatorname{Pr}(T=2)=\Phi\left(\mu_{2}-\beta x\right)-\Phi\left(\mu_{3}-\beta x\right) \\
T=1 & \text { if } & \mu_{2}<C^{*} \leq \mu_{1} \& \operatorname{Pr}(T=1)=\Phi\left(\mu_{1}-\beta x\right)-\Phi\left(\mu_{2}-\beta x\right) \\
T=0 & \text { if } & C^{*}>\mu_{1} & \& \operatorname{Pr}(T=0)=1-\Phi\left(\mu_{1}-\beta x\right)=\Phi\left(\beta x-\mu_{1}\right)
\end{array}
$$

where $\mu_{k}$ are latent threshold values of generalized cost. Equation (2) follows directly from the ordered-probit specification provided by McKelvey and Zavoina (1975).

Distance travelled, on the other hand, can be considered as a continuous random variable. Considering total distance travelled, $D$, as a logarithmic function (ensuring non-negativity of distance), this can be specified as:

$$
\ln (D)=\gamma y+\eta
$$

where, $y$ is the vector of explanatory variables, $\gamma$ is the vector of corresponding coefficients, and $\eta$ is the unobserved error term. If the number of trips generated is classified as $0,1,2$, and $3+$ and corresponding distances travelled are $0, D_{1}, D_{2}$, and $D_{3}$, the joint probabilities of trip generation and corresponding distance travelled can be specified as: 


$$
\begin{aligned}
& \operatorname{Pr}\left(T=3+\& D=D_{3}\right)=\operatorname{Joint} \operatorname{Pr}\left(C^{*} \leq \boldsymbol{\mu}_{3}+\& D=D_{3}\right) \\
& \operatorname{Pr}\left(T=2 \& D=D_{2}\right)=\operatorname{Joint} \operatorname{Pr}\left(C^{*} \leq \boldsymbol{\mu}_{2} \& D=D_{2}\right)-\operatorname{Joint} \operatorname{Pr}\left(C^{*} \leq \boldsymbol{\mu}_{3} \& D=D_{3}\right) \\
& \operatorname{Pr}\left(T=1 \& D=D_{1}\right)=\operatorname{Joint} \operatorname{Pr}\left(C^{*} \leq \boldsymbol{\mu}_{1} \& D=D_{1}\right)-\operatorname{JointPr}\left(C^{*} \leq \boldsymbol{\mu}_{2} \& D=D_{2}\right) \\
& \operatorname{Pr}(T=0 \& D=0)=\mathbf{1}-\operatorname{Joint} \operatorname{Pr}\left(C^{*}>\boldsymbol{\mu}_{\mathbf{1}}\right)
\end{aligned}
$$

Consider the specifications for the error terms. We assume that $\varepsilon$ is normally distributed with zero mean and unit variance and the random error of continuous distance, $\eta$ is normally distributed with zero mean and variance, $\sigma^{2}$. Correlations between unobserved factors of these two decisions are addressed by positing that $\varepsilon$ and $\eta$ are bivariate normal distributed with covariance matrix $\Sigma=\left[\begin{array}{cc}1 & \rho \sigma \\ \rho \sigma & \sigma\end{array}\right]$. Probabilities of individual orders of trip making are defined in equation (2). In order to ensure that the model never predicts a negative distance value, we assumed that distance follows a log-normal distribution.

In order to estimate the parameters, $\beta, \gamma$, and $\sigma$, the joint probabilities are derived considering the correlation between the two types of decisions specified in equation (4). So, the joint likelihood $(L)$ for any one observation becomes:

$$
\begin{aligned}
& L=I(T=3+)\left\{\left[\frac{1}{\sigma D_{3}} \phi\left(\frac{\ln \left(D_{3}\right)-\gamma y}{\sigma}\right) \Phi\left(\frac{u_{3}-\beta x-\rho\left(\frac{\left(\ln \left(D_{3}\right)-\gamma y\right)}{\sigma}\right)}{\sqrt{1-\rho^{2}}}\right)\right]\right\}+I(T= \\
& \text { 2) }\left\{\left[\frac{1}{\sigma D_{2}} \phi\left(\frac{\ln \left(D_{2}\right)-\gamma y}{\sigma}\right) \Phi\left(\frac{u_{2}-\beta x-\rho\left(\frac{\left(\ln \left(D_{2}\right)-\gamma y\right)}{\sigma}\right)}{\sqrt{1-\rho^{2}}}\right)\right]-\left[\frac{1}{\sigma D_{3}} \phi\left(\frac{\ln \left(D_{3}\right)-\gamma y}{\sigma}\right) \Phi\left(\frac{u_{3}-\beta x-\rho\left(\frac{\left(\ln \left(D_{3}\right)-\gamma y\right)}{\sigma}\right)}{\sqrt{1-\rho^{2}}}\right)\right]\right\}+ \\
& I(T=1)\left\{\left[\frac{1}{\sigma D_{1}} \phi\left(\frac{\ln \left(D_{1}\right)-\gamma y}{\sigma}\right) \Phi\left(\frac{u_{1}-\beta x-\rho\left(\frac{\left(\ln \left(D_{1}\right)-\gamma y\right)}{\sigma}\right)}{\sqrt{1-\rho^{2}}}\right)\right]-\left[\frac{1}{\sigma D_{2}} \phi\left(\frac{\ln \left(D_{2}\right)-\gamma y}{\sigma}\right) \Phi\left(\frac{u_{2}-\beta x-\rho\left(\frac{\left(\ln \left(D_{2}\right)-\gamma y\right)}{\sigma}\right)}{\sqrt{1-\rho^{2}}}\right)\right]\right\}+ \\
& I(T=0)\left\{\Phi\left(\beta x-\mu_{1}\right)\right\}
\end{aligned}
$$

where $I(\cdot)$ is an indicator function, $\rho$ is the correlation between the two random error terms, and subscripts of $D$ indicate total distances travelled for corresponding numbers of trips generated.

Now for $N$ observations, the log-likelihood $(L L)$ of the sample becomes:

$$
L L=\sum_{i=1}^{N} \ln (L)
$$

The log-likelihood function is estimated and maximized with code written in MATLAB. The standard errors of the parameters are calculated using the inverse Hessian procedure. The goodness of fit of the models is estimated using an adjusted likelihood ratio test:

$$
\bar{\rho}^{2}=1-\frac{L L^{*}-k}{L L_{R}}
$$

where $L L^{*}$ is the log-likelihood at convergence, $L L_{R}$ is the log-likelihood of the restricted constants-only model, and $k$ indicates the number of parameters in the fully specified model minus the number of parameters in the restricted model. Application of the model is very 
straightforward. The correlation parameter $\rho$ does not enter into the individual probability functions of the ordered probit and hazard models. It only enters into the joint probability function to derive a likelihood function that eliminates estimation bias. Hence, the model can be used to forecast trip generation frequency and total distance travelled by applying equations 2 and 3 directly to estimated regression coefficients and known characteristics of individuals, $x$ and $y$. Importantly, we do not need to simulate the correlated residuals in order to make these forecasts.

\section{RESULTS}

The results of the joint ordinal-continuous regression model appear in Table 3. A selection of variables describing personal and household characteristics was used to calibrate the model. Factors of particular relevance to social equality (low income, elderly, low education, employment status, race, and others) were spatially expanded using distance to the CBD and a polynomial function of the household spatial coordinates (denoting longitude and latitude with $u, v$, respectively) following Casetti (1972) and a slew of recent transportation studies (Paez et al., 2010; Morency et al., 2009; Farber et al.. 2012). The expansion method captures spatial non-stationarity that may exist in the relationships between dependent and independent variables without resorting to semi- and non-parametric techniques, such as Geographically Weighted Regression (Brunsdon et al., 1996).

Stepwise selection on each non-joint model was used to inform the selection of variables that appear in the joint specification. Many variables that attain significance in the non-joint models no longer add explanatory power in the joint specification, evidence that the introduction of the correlated residuals produce more efficient estimators. Variables that retain significance at the $\alpha=0.3$ level were kept in the model. The final model specification depends on 55 independent variables plus five parameters that are used to specify the thresholds of the ordinal model $\left(\mu_{1}-\mu_{3}\right)$, the variance of residuals $(\sigma)$, and the correlation used to specify the bivariate normal residuals $(\rho)$. The model obtains an adequate fit as characterized by a significant test of the likelihood ratio, a McFadden's $\bar{\rho}^{2}$ of 0.114 , and a pseudo- $r^{2}$ of distance travelled of 0.58 .

Interpretation of the regression coefficients follow from the normal ways to interpret ordinal probit and OLS regression coefficients for the trip generation and distance travelled models, respectively. In the ordered probit case, negative coefficients indicate lower generalized costs of taking transit, and therefore higher propensity to make more trips. According to the results, factors most strongly associated with taking more trips include being 18-24 years old; living in a household with retirees for household heads; being a student who is employed for more than 25 hours per week; being highly educated; living in a zero-vehicle household; living in larger households; and living in a suburban neighborhood that maintains a high mix of land uses (self-reported). Variables that decrease the propensity to take transit include being younger than 18; being self-employed; being female; living in households with two or more vehicles; living in households that are neither rented nor owned; living in households with many children's bicycles; and living in households that are farther away from long-distance commuter rail (presumably because the commuter-rail only serviced a small fraction of suburbs at the time of the data collection). 
TABLE 4.1: Results of the Joint Ordinal/Continuous Model for Public Transit Trip Generation and Distance Travelled

Ordered Model Estimates

Continuous Model Estimates
Age less than 17 years

Age 18-24 years

Age over $65 * u^{2}$

Age over $65 * v^{2}$

Mobility Limitation * $v$

Household w/ retirees

Self employed

Student, emp. 25+ hrs/week

Unemployed/retired $* u^{2}$

Unemployed/retired $* u$

Grad. or post-grad. degree

Female

Hispanic

Hispanic $* v$

Hispanic $* v^{2}$

No driver's license

No driver's license * $v$

Zero vehicle household

2 vehicle household

$3+$ vehicle household

Income $<\$ 25 \mathrm{~K} * u v$

Income - Refusal

Household rents * D_CBD

Household rents * uv

Household Tenure - Other

Household Tenure - Refusal

$3+$ workers

$3+$ children's bikes

$6+$ people

Suburban mixed neighborhood

Distance to Commuter Rail

$u^{2}$

\begin{tabular}{|c|c|c|c|c|}
\hline B & p-value & & B & p-value \\
\hline 0.9052 & 0.0000 & Constant & -3.9564 & 0.0000 \\
\hline-0.1468 & 0.0607 & Two transit trips & 1.1045 & 0.0000 \\
\hline 1.4356 & 0.0193 & Three transit trips & 1.5018 & 0.0000 \\
\hline 0.8022 & 0.0167 & Age over 65 & -0.2700 & 0.1709 \\
\hline-0.3858 & 0.0956 & No children or retirees & -0.1596 & 0.0821 \\
\hline-0.3449 & 0.0004 & Student, em. $<25$ hrs/week & -0.2771 & 0.1868 \\
\hline 0.9011 & 0.0000 & $\begin{array}{l}\text { Unemployed/retired } \\
\text { High school or less * }\end{array}$ & -0.2670 & 0.0483 \\
\hline-0.4158 & 0.0000 & D_CBD & -0.0072 & 0.0619 \\
\hline-1.1084 & 0.2099 & Hispanic - Refusal & -0.5133 & 0.0464 \\
\hline 1.8918 & 0.0003 & Race: non-white * D_CBD & 0.0199 & 0.0052 \\
\hline-0.3251 & 0.0000 & Race: non-white $* v$ & -0.4355 & 0.1926 \\
\hline 0.1842 & 0.0001 & Zero vehicles * D_CBD & -0.0132 & 0.0275 \\
\hline 1.1440 & 0.0446 & Income $<\$ 25 \mathrm{~K} * u v$ & -0.8834 & 0.0818 \\
\hline-1.2459 & 0.0902 & Income $\$ 75-\$ 100 \mathrm{~K}$ & -0.4831 & 0.0001 \\
\hline-2.4449 & 0.0011 & 4 people & 0.1759 & 0.1779 \\
\hline-1.3931 & 0.0000 & $3+$ workers & 0.2371 & 0.0917 \\
\hline 1.4272 & 0.0016 & $3+$ children's bikes & 0.2400 & 0.1706 \\
\hline-0.7612 & 0.0000 & $5+$ years in current res. & 0.1163 & 0.1723 \\
\hline 0.3455 & 0.0000 & City, residential neigh. & -0.1825 & 0.0500 \\
\hline 0.5623 & 0.0000 & Distance to CBD & 0.0522 & 0.0000 \\
\hline-0.5827 & 0.1106 & Distance to bus stop & 0.1788 & 0.0003 \\
\hline 0.1421 & 0.1002 & $v$ & 17.4178 & 0.0000 \\
\hline 0.0087 & 0.0001 & $v^{2}$ & -15.0180 & 0.0000 \\
\hline-1.1271 & 0.0004 & \multicolumn{3}{|c|}{ Joint Model Parameter Estimates } \\
\hline 0.6485 & 0.1282 & & B & p-value \\
\hline 0.8261 & 0.0700 & $\mu_{1}$ & -1.3672 & 0.0000 \\
\hline-0.1580 & 0.0740 & $\mu_{2}$ & -1.5167 & 0.0000 \\
\hline 0.2259 & 0.0186 & $\mu_{3}$ & -2.4753 & 0.0000 \\
\hline-0.2206 & 0.0076 & $\rho$ & -0.1883 & 0.0625 \\
\hline-0.1226 & 0.0211 & $\sigma$ & 0.8322 & 0.0000 \\
\hline 0.0024 & 0.2466 & & & \\
\hline 0.4476 & 0.0410 & & & \\
\hline
\end{tabular}

Log-Likelihood: -3701.04; $\quad \mathrm{p}\left(\chi^{2}\right)<0.0000 ; \quad$ McFadden's Adj. $\bar{\rho}^{2}: 0.1144 ; \quad$ pseudo- $r^{2}=0.5782 ; \quad n=16071$ 
Many coefficients were insignificant on their own, but became significant in the presence of one of the spatial expansion terms. Significant spatially expanded factors include being older than 65; having a mobility limitation; being unemployed or retired; being Hispanic; not having a driver's license; and being low-income and living in a rented house. These factors are all salient to the equitable distributions of transit costs; understanding their spatial heterogeneous effects on trip generation and distance travelled is an important precursor to assessing the equity of distance-based fares. While it is possible to view maps of these coefficient surfaces, for the sake of brevity visual analysis of results will be reserved for distances travelled and fares.

The continuous portion of the model contains 20 independent variables. The dependent variable is $\ln$ (distance) and most of the variables are binary indicators of factor levels. Thus for a binary variable, a change from 0 to 1 indicates a 100* $\beta$ percent change in distance travelled. In other words, individuals who take two and three transit trips, respectively, travel $110 \%$ and $150 \%$ farther than those who only take one trip. Other non-expanded factors that predict increased distance travelled include living in a larger household with multiple workers; having lived in one's residence for five or more years; and living farther away from the central business district and near a bus stop. Non-expanded factors that are associated with less distance travelled include being older than 65; living in a household without children or retirees; being a student with limited or no outside employment; being unemployed or retired; living in a high-income household; and living in a residential city neighborhood (self-reported). The factors that are significant when expanded include low-education, low-income, non-white, and zero-vehicle households. As before, the spatially expanded coefficients are difficult to interpret directly, but in Figure 1 we illustrate their impact on distance travelled using maps.

Before continuing, it is necessary to define the reference case respondent in the distancetravelled model. This is the profile of the respondent for which all dummy variables are set to zero. The reference individual is a white, non-Hispanic male, aged 35-44. He is employed full time with a bachelor's degree; lives in a house with one car, two adults and no children; and has a household income between $\$ 50,000$ and $\$ 75,000$ per year, which he earns as the sole worker in the family. He has a driver's license and no bicycles. He owns a single-detached house in an urban but residential neighborhood that he has lived in for less than a year. Given such a profile, the map in Figure 1A provides an indication of the distance such a person would travel by transit given two daily trips. Estimated distances travelled increase with distance to the CBD and bus lines. Figure 1B is for individuals who have high-school or less education living in zero-vehicle households with incomes below $\$ 25,000$ per year. Figure 1C is for unemployed, elderly individuals with incomes less than $\$ 25,000$. And Figure 1D is for non-white individuals who elected not to identify their Hispanic status. While the general spatial patterns of estimated distances travelled are similar, important differences do exist. For example, distances for lowincome and elderly individuals are shorter than for the more mobile reference category, both in the core of the city, as well in the peripheral suburban towns. Distances for the non-white category have short distances in the center of the city, but estimated distances are actually larger than those for the reference category in the southward direction. These spatial patterns, while interesting in their own right, can be made more directly useful by converting figures into estimated distance-based transit costs, and comparing distance-based fares to the current static fares charged by the UTA. 

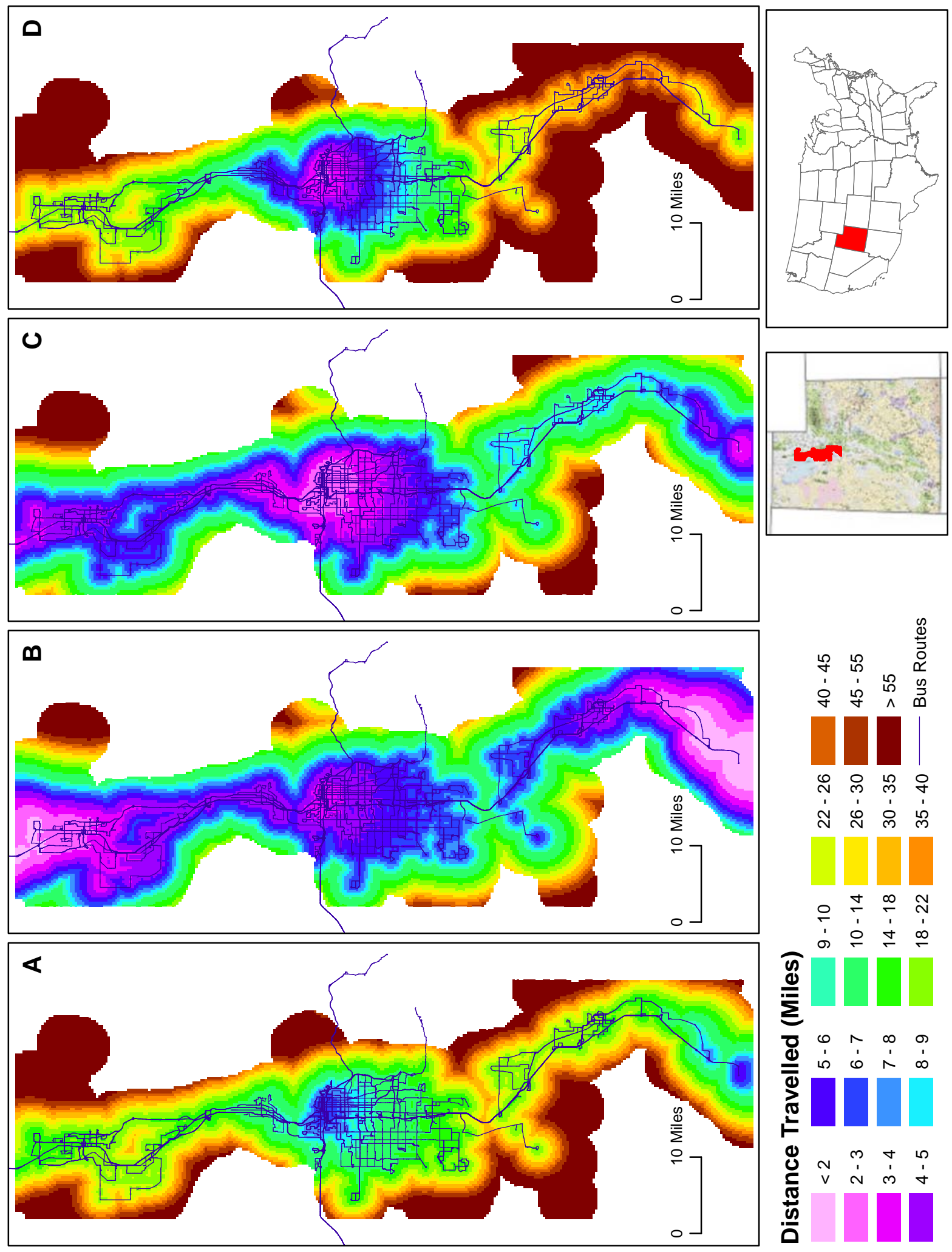

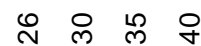

N

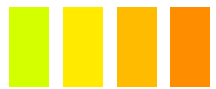

억 $\stackrel{\infty}{-} \underset{\sim}{-1}$

ద

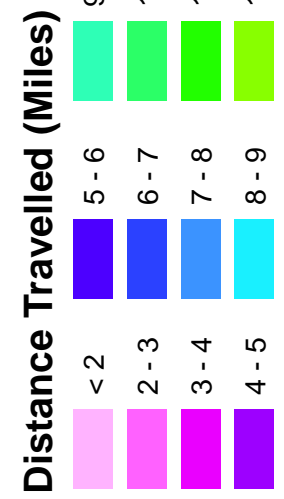

FIGURE 4.1 Expected Distances Travelled by Public Transit for Socioeconomic Profiles A) Reference Group, B) Low Income and Education, C) Low Income/Elderly D) Non-White 
Distance-based fares are commonly structured around a nominal fee per trip plus a distance-based component. Based on the 787 transit trips observed in our dataset, we can generate revenue-neutral pricing schemes where the overall revenue collected under the distancebased fare structure equals the amount collected using flat fares. Assuming, for now, no price elasticity in ridership, revenue neutral fare structures must be solutions to the following equation:

\section{2. $5 T=a+b D$}

where 2.5 is the fare per trip under the flat-fare pricing structure, $T$ is the total number of linked trips taken, $a$ is the new fee per trip and $b$ is the fare per mile of travel. Given $T$ and $D$ from our survey, we find that all revenue neutral distance-based fares are defined by the line:

$$
b=0.2377-0.0951 a
$$

For example, if the nominal fee per trip was $\$ 1$, then the fare per mile should be set to about 14 cents. Intuitively, based on our knowledge of travel behavior (i.e., trip generation and distances travelled) fare structures with a high fixed price and low distance-based price (with flat fares being an extreme of this type) will disproportionately favor long distance, predominantly wealthier riders. Without loss of generality, for the remainder of the analysis we will continue to work with a fare of 50 cents plus 19 cents per mile travelled.

Under this fare scenario, we can calculate the average flat and distance-based fares for individuals based on the summary trip-making statistics found in Table 1 (see Table 4). According to these averages, it is quite apparent that distance-based fares progressively provide price reductions to those who need it most, and ask those in higher socioeconomic positions to pay more for their travel. However, despite the overall equity impact of distance-based fares being quite positive, our model can be used to calculate the expected change in fares paid by individuals of a specific demographic profile, differentiated by residential location. Such fares can be found in Figure 2 for the profiles A-D, as described above. In these surfaces, green colors denote cost savings, reds denote cost increases, and the bright blue shade denotes cost parity, where the expected transit fare is about equal under the two fare structures. The reader will see that many areas within the region, for these four profiles, lie within the cost-parity ring, indicating an expected cost saving for most inhabitants. This is especially true for the lowincome and elderly subgroups (maps B and C), but less so for the wealthier reference profile in map A and the non-white profile in map D. For the latter, the model estimates cost increases for many living outside the central urbanized area of Salt Lake County. Such spatial disparities are masked by the spatial averaging taking place in Table 4, which is precisely why an approach based on a model is preferred to one based on descriptive statistics.

Figure 3 provides a closer look at the cost increases for non-white and Hispanic individuals. On top of identifying areas of cost increases, we overlay the top $20 \%$ of census tracts in terms of non-white and Hispanic populations. We include the high Hispanic tracts under the assumption that many survey respondents who refused to identify their Hispanic status are, in fact, of Hispanic ethnicity. The overlay clearly identifies tracts in Provo (to the south), Ogden (to the north), and in the region between Magna and West Jordan (to the west) where non-white and Hispanic transit users may experience cost increases as a result of shifting to distance-based fares. It should be mentioned that, according to the trip survey data, fares for Hispanic respondents on average declined by $9 \%$, and by $55 \%$ amongst those who refused to state their status. Clearly, this very large decline is a function of the very short trips taken by the refusal group, who on average travel only 5.3 miles each day. 
TABLE 3.2 Average Fare Change for Different Population Groups

\begin{tabular}{|c|c|c|c|c|c|}
\hline & $\begin{array}{c}\text { Transit } \\
\text { Trips } \\
\end{array}$ & $\begin{array}{c}\text { Distance } \\
\text { Travelled } \\
\text { (miles) }\end{array}$ & $\begin{array}{c}\text { Flat } \\
\text { Fare }^{a} \\
(\$) \\
\end{array}$ & $\begin{array}{c}\text { Distance- } \\
\text { Based } \\
\text { Fare }^{b} \\
(\$)\end{array}$ & $\begin{array}{l}\text { Percentage } \\
\text { Change }\end{array}$ \\
\hline \multicolumn{6}{|l|}{ Household Income } \\
\hline No Answer & 1.73 & 20.09 & 4.33 & 4.68 & $8.3 \%$ \\
\hline Under $\$ 35,000$ & 1.94 & 13.25 & 4.85 & 3.49 & $-28.1 \%$ \\
\hline$\$ 35,000-\$ 49,999$ & 1.88 & 19.14 & 4.70 & 4.58 & $-2.6 \%$ \\
\hline$\$ 50,000$ - $\$ 99,999$ & 1.85 & 20.56 & 4.63 & 4.83 & $4.5 \%$ \\
\hline$\$ 100,000$ or more & 1.86 & 24.51 & 4.65 & 5.59 & $20.1 \%$ \\
\hline \multicolumn{6}{|l|}{ Hispanic } \\
\hline Yes & 1.89 & 17.39 & 4.73 & 4.25 & $-10.1 \%$ \\
\hline No & 1.88 & 19.6 & 4.70 & 4.66 & $-0.8 \%$ \\
\hline Prefer not to answer & 1.64 & 5.34 & 4.10 & 1.83 & $-55.3 \%$ \\
\hline \multicolumn{6}{|l|}{ Race } \\
\hline White or Caucasian & 1.89 & 19.93 & 4.73 & 4.73 & $0.1 \%$ \\
\hline All other & 1.77 & 14.25 & 4.43 & 3.59 & $-18.8 \%$ \\
\hline \multicolumn{6}{|l|}{ Age } \\
\hline 18-24 years old & 1.82 & 17.47 & 4.55 & 4.23 & $-7.0 \%$ \\
\hline $25-34$ years old & 1.88 & 17.51 & 4.70 & 4.27 & $-9.2 \%$ \\
\hline $35-44$ years old & 1.84 & 24.19 & 4.60 & 5.52 & $19.9 \%$ \\
\hline 45-54 years old & 1.87 & 19.73 & 4.68 & 4.68 & $0.2 \%$ \\
\hline 55-64 years old & 1.88 & 17.82 & 4.70 & 4.33 & $-8.0 \%$ \\
\hline$>65$ years old & 2.08 & 13.91 & 5.20 & 3.68 & $-29.2 \%$ \\
\hline \multicolumn{6}{|l|}{ Employment } \\
\hline Employed full-time & 1.84 & 22.43 & 4.60 & 5.18 & $12.6 \%$ \\
\hline Employed part-time & 1.84 & 13.61 & 4.60 & 3.51 & $-23.8 \%$ \\
\hline $\begin{array}{l}\text { Student, not employed or employed } \\
\text { less than } 25 \mathrm{hrs} / \text { week }\end{array}$ & 1.76 & 15.96 & 4.40 & 3.91 & $-11.1 \%$ \\
\hline Student, employed $25+$ hrs/week & 1.91 & 14.61 & 4.78 & 3.73 & $-21.9 \%$ \\
\hline All Other & 2.00 & 13.88 & 5.00 & 3.64 & $-27.3 \%$ \\
\hline \multicolumn{6}{|l|}{ Education } \\
\hline High school or less & 1.85 & 13.08 & 4.63 & 3.41 & $-26.3 \%$ \\
\hline $\begin{array}{l}\text { Some } \\
\text { College/Vocational/Associates }\end{array}$ & 1.87 & 18.56 & 4.68 & 4.46 & $-4.6 \%$ \\
\hline Bachelors & 1.80 & 19.34 & 4.50 & 4.57 & $1.7 \%$ \\
\hline Grad/Post Grad & 1.95 & 21.88 & 4.88 & 5.13 & $5.3 \%$ \\
\hline
\end{tabular}

${ }^{a}$ Flat fares are based on a price of $\$ 2.50$ per trip.

${ }^{b}$ Distance based fares are based on a price of 50 cents per trip plus 19 cents per mile of travel. 

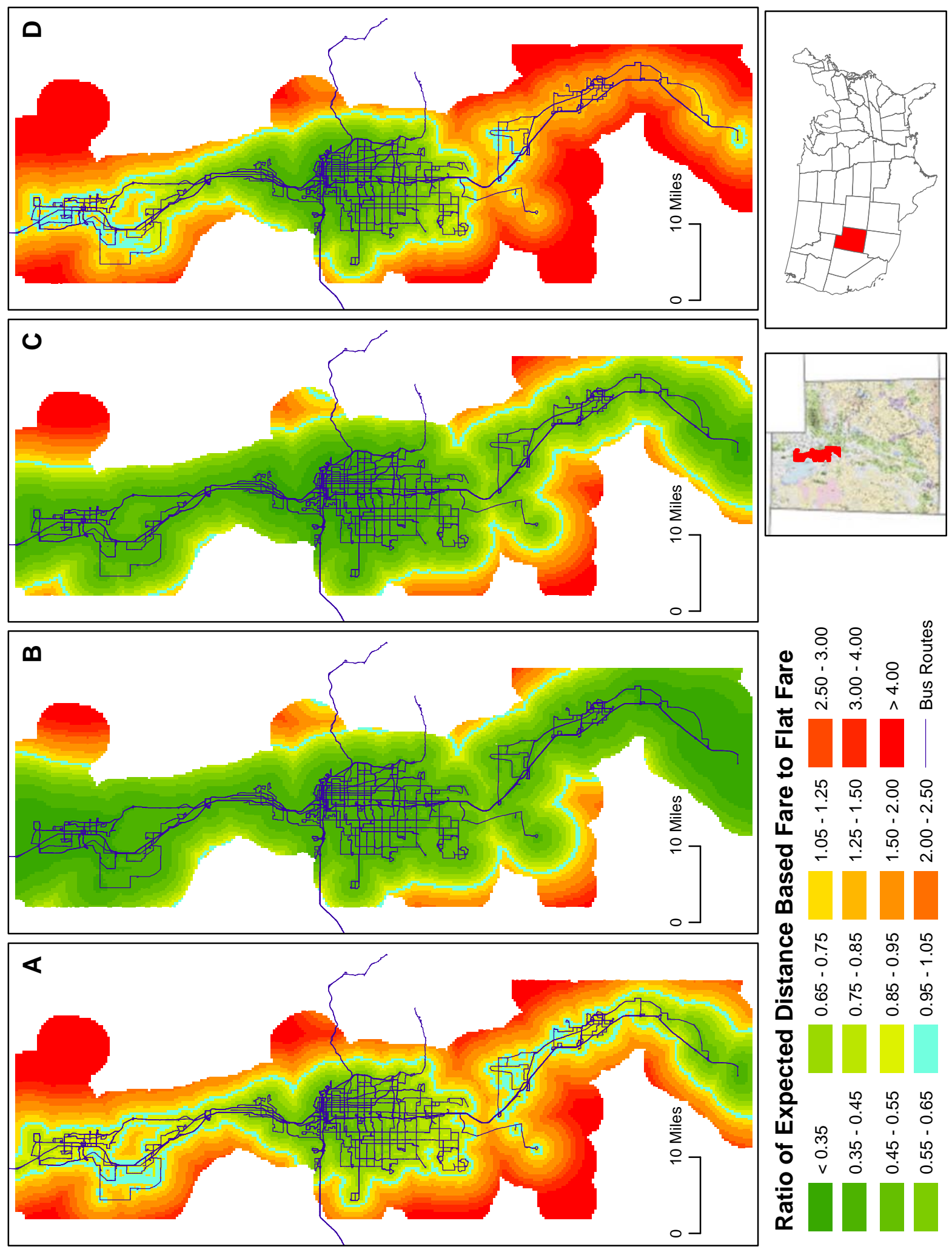

FIGURE 4.2: Expected Change in Fare for Travelers Taking Two Transit Trips in a Day A) Reference Group, B) Low Income+Education, C) Low Income/Elderly D) Non-White 


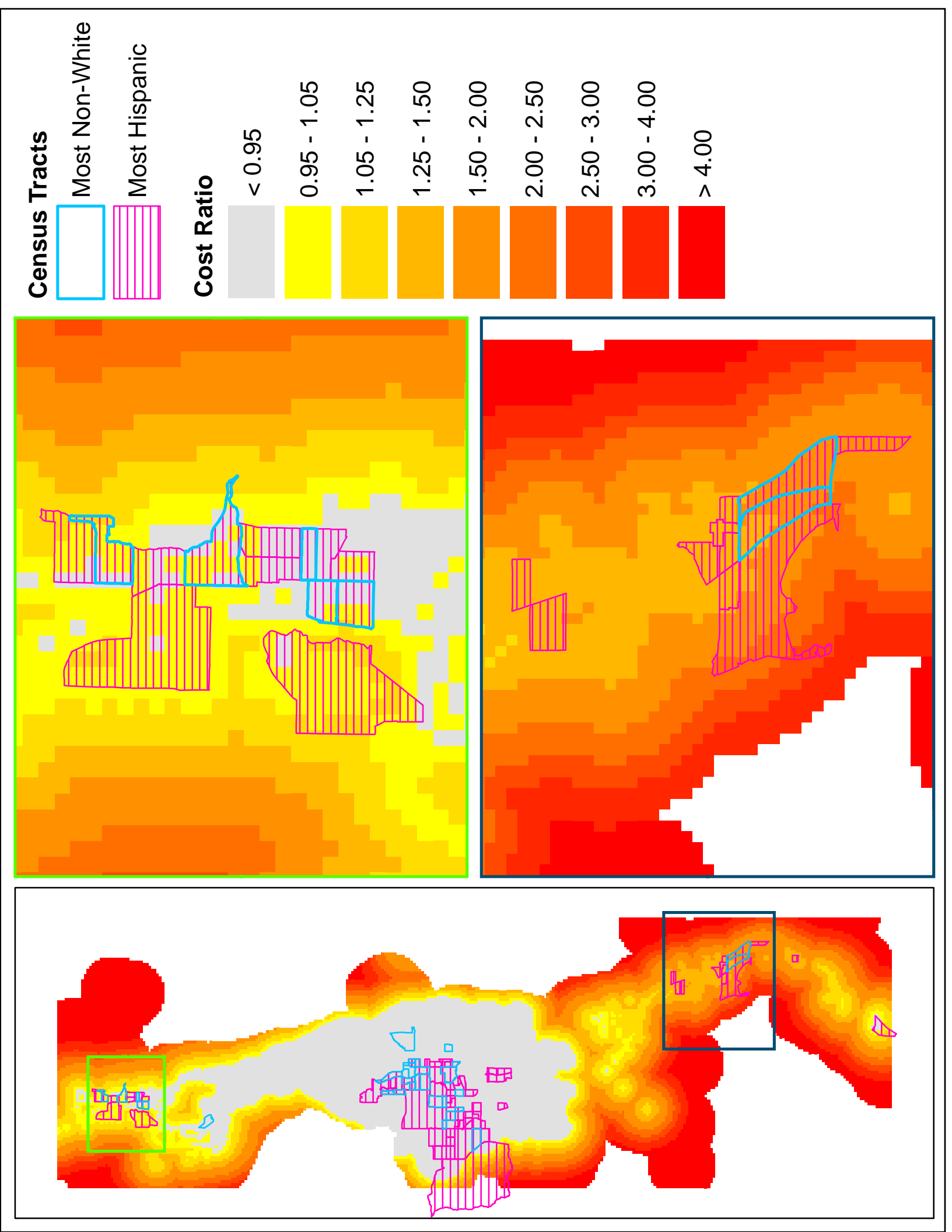

FIGURE 4.3 Fare Increases for Non-White and Hispanic Travelers Overlaid with Non-White and Hispanic Census Tracts 


\section{CONCLUSIONS}

The tabular and graphical results presented above constitute the skeleton of a screening mechanism for identifying inequalities inherent in transit pricing structures. For two of the most transit-dependent populations, low-income households and the elderly, we find that given their expected trip-making rates and distances, the distance-based fare we analyzed is expected to lower their costs for public transit. The screening mechanism, however, identified locations far away from the central business district, where fares charged to non-white (and potentially Hispanic) travelers may increase. These screened locations were few compared to the dense concentration of non-white and Hispanic census tracts near the center of the city, where fares are more likely to decrease. In order to better understand the potential impact distance-based fares may have on this population, we recommend that a follow-up study of transit use be carried out in a number of suburban, minority and low-income neighborhoods. Such neighborhoods can be identified through continued exploration of transit fare maps for different socio-demographic profiles.

The work conducted has some limitations. The kernel of the research relies on an accurate behavioral model of trip generations and distances travelled, and we must provide several caveats concerning the data and model specification. First, the Utah Household Travel Survey provides only a limited one-day snapshot of travel for each responding household. There is arguably much intrapersonal variation in transit use throughout the week, and this is lost by not capturing longer-term travel patterns. Second, the trip records are geocoded at trip ends, but detailed routing information is not captured by the web-based survey instrument. This means that actual distances travelled along the transit network are not known and must be imputed based on shortest paths or otherwise approximated using common sense. The error associated with these imputations may have a limited impact on estimated costs. Third, the trip generation and distance models were calibrated without a price variable, implicitly assuming that travelers are not sensitive to price. We did not explore the impact of fares on ridership because the goal of our study is to derive a transferable methodology that satisfies Title VI obligations. While price elasticity is an important aspect of a revenue-based study of fares, and likely has ramifications on social equity from the perspective of captive and discretionary ridership, it is not a requirement of Title VI analyses, and therefore remains the subject of potential future research. Finally, we caution that with the growing trend of decentralized poverty across the United States, a followup social equity analysis of distance-based fares would benefit from the incorporation of estimated and projected population characteristics. Furthermore, while the findings related to spatiality and transit use discovered in this research are valid, the ability to transfer results to other regions with different spatial demographic patters is limited.

The technique developed to explore distance-based fares in this paper is novel. It is part of a growing body of research that specifically focuses on the societal implications of travel through the innovative adaptation of data and methods originally designed for travel behavior modeling. It combines state-of-the-art econometric models of travel behavior with spatial analysis and GIS. The next step of the work is to package the above-demonstrated functionality into a GIS decision support system. Using an intuitive graphical user interface, this system will enable transit planners at the UTA to visualize and compare distance-travelled and transit-cost maps for different socio-demographic profiles and fare structures. 


\section{REFERENCES}

Ballou, D. P., and L. Mohan. A decision model for evaluating transit pricing policies. Transportation Research Part A: General, Vol. 15, No. 2, 1981, pp. 125-138.

Bocarejo, S. J. P., and H. D. R. Oviedo. Transport accessibility and social inequities: a tool for identification of mobility needs and evaluation of transport investments. Journal of Transport Geography, Vol. 24, 2012, pp. 142-154.

Boschmann, E. E., and M. P. Kwan. Toward Socially Sustainable Urban Transportation: Progress and Potential. International Journal of Sustainable Transportation, Vol. 2, No. 3, 2008, pp. 138-157.

Brunsdon, C., A. S. Fotheringham, and M. E. Charlton. Geographically Weighted Regression: A Method for Exploring Spatial Nonstationarity. Geographical Analysis, Vol. 28, No. 4, 1996, pp. 281-298.

Bullard, R. D., G. S. Johnson, and A. O. Torres. Highway Robbery: Transportation Racism \& New Routes to Equity.In, South End Press, Cambridge, MA, 2004.

Casetti, E. Generating Models by the Expansion Method: Applications to Geographical Research. Geographical Analysis, Vol. 4, No. 1, 1972, pp. 81-91.

Cervero, R. The transit pricing evaluation model: A tool for exploring fare policy options. Transportation Research Part A: General, Vol. 16, No. 4, 1982, pp. 313-323.

Cervero, R. Transit pricing research. Transportation, Vol. 17, No. 2, 1990, pp. 117-139.

Currie, G. Quantifying spatial gaps in public transport supply based on social needs. Journal of Transport Geography, Vol. 18, No. 1, 2010, pp. 31-41.

Daskin, M. S., J. L. Schofer, and A. E. Haghani. Optimizing Model for Transit Fare Policy Design and Evaluation. Transportation Research Record, Vol. 1039, 1985, pp. 32-42.

Deakin, E., and G. Harvey. Transportation Pricing Strategies for California: An Assessment of Congestion, Emissions, Energy and Equity Impacts, Final Report.In, California Air Resources Board, Sacramento, CA, 1996.

Deb, K., and M. Filippini. Estimating welfare changes from efficient pricing in public bus transit in India. Transport Policy, Vol. 18, No. 1, 2011, pp. 23-31.

Deka, D. Social and Environmental Justice Issues in Urban Transportation.In The Geography of Urban Transportation, Guilford Press, New York, 2004. pp. 332-355.

Fan, Y., and A. Huang. How Affordable is Transportation? A Context-Sensitive Framework.In Center for Transportation Studies Research Report, No. CTS 11-12, University of Minnesota, 2011.

Farber, S., and A. Páez. Activity Spaces and the Measurement of Clustering: A Case Study of Crosslinguistic Exposure in Montreal. Environment and Planning A, Vol. 44, No. 2, 2012, pp. 315-332.

Federal Transit Administration. Environmental Justice Policy Guidance for Federal Transit Administration Recipients, FTA C 4703.1, 2012. 
Frumkin, H. Urban sprawl and public health. Public Health Reports, Vol. 117, No. 3, 2002, pp. 201-217.

Garrett, M., and B. Taylor. Reconsidering Social Equity in Public Transit. Berkeley Planning Journal, Vol. 13, 1999, pp. 6-27.

Giuliano, G. Equity and Fairness Considerations of Congestion Pricing.In Transportation Research Board Special Report, No. 242, 1994.

Haas, P. M., C. Makarewicz, A. Benedict, T. W. Sanchez, and C. J. Dawkins. Housing \& Transportation Cost Trade-offs and Burdens of Working Households in 28 Metros.In, Center for Neighborhood Technology, 2006.

Hickey, R. L., A. Lu, and A. Reddy. Using Quantitative Methods in Equity and Demographic Analysis to Inform Transit Fare Restructuring Decisions. Transportation Research Record, No. 2144, 2010, pp. 80-92.

Jorgensen, F., and J. Preston. The Relationship Between Fare and Travel Distance. Journal of Transport Economics and Policy, Vol. 41, No. 3, 2007, pp. 451-468.

King, D. A. Remediating Inequity in Transportation Finance.In Transportation Research Board Special Report, No. 303, 2011.

Kucheva, Y. A. Subsidized Housing and the Concentration of Poverty, 1977-2008: A Comparison of Eight US Metropolitan Areas. City \& Community, Vol. 12, No. 2, 2013, pp. 113-133.

Lam, W. H. K., and J. Zhou. Optimal Fare Structure for Transit Networks with Elastic Demand. Transportation Research Record, Vol. 1733, 2000, pp. 8-14.

Li, Z., W. H. K. Lam, S. C. Wong, and A. Sumalee. Design of a rail transit line for profit maximization in a linear transportation corridor. Transportation Research Part E: Logistics and Transportation Review, Vol. 48, No. 1, 2012, pp. 50-70.

Litman, T., and M. Brenman. A New Social Equity Agenda For Sustainable Transportation.In, Victoria Transport Policy Institute, Victoria, 2011.

Litman, T. Evaluating Transportation Equity. World Transport Policy \& Practice, Vol. 8, No. 2, 2002, pp. 50-65.

Lucas, K. Towards a 'social welfare' approach to transport.In Running on empty: transport, social exclusion and environmental justice, Policy, Bristol, 2004. pp. 291-298.

Martens, K. Justice in transport as justice to access: applying Walzer's "Spheres of Justice" to the transport sector. Presented at 88th Annual Meeting of the Transportation Research Board, Washington, DC, USA, 2009.

Massey, D. S., and M. J. Fischer. How segregation concentrates poverty. Ethnic and Racial Studies, Vol. 23, No. 4, 2000, pp. 670-691.

McKelvey, R. D., and W. Zavoina. A statistical model for the analysis of ordinal level dependent variables. Journal of Mathematical Sociology, Vol. 4, No. 1, 1975, pp. 103-120.

Morency, C., A. P ez, M. J. Roorda, R. G. Mercado, and S. Farber. Distance traveled in three Canadian cities: Spatial analysis from the perspective of vulnerable population segments. Journal of Transport Geography, 2009. 
Nuworsoo, C., A. Golub, and E. Deakin. Analyzing equity impacts of transit fare changes: Case study of Alameda-Contra Costa Transit, California. Evaluation and Program Planning, Vol. 32, No. 4, 2009, pp. 360-368.

Páez, A., K. M. Nurul Habib, and J. Bonin. A joint ordinal-continuous model for episode generation and duration analysis. 88th Annual Meetings of the Transportation Research Board, 2008.

Páez, A., R. G. Mercado, S. Farber, C. Morency, and M. J. Roorda. Relative Accessibility Deprivation Indicators for Urban Settings: Definitions and Applications to Food Deserts in Montreal. Urban Studies, 2010.

Plotnick, R. D., J. Romich, J. Thacker, and M. Dunbar. A Geography-Specific Approach to Estimating the Distributional Impact of Highway Tolls: An Application to the Puget Sound Region of Washington State. Journal of Urban Affairs, Vol. 33, No. 3, 2011, pp. 345-366.

Sanchez, T. W., and M. Brenman. The Right to Transportation: Moving to Equity. APA Planners Press, Chicago, 2007.

Taylor, B. The Geography of Urban Transportation Finance.In The Geography of Urban Transportation, Guilford Press, New York, 2004. pp. 294-331.

Tsai, F., S. I. Chien, and L. N. Spasovic. Optimizing Distance-Based Fares and Headway of an Intercity Transportation System with Elastic Demand and Trip Length Differentiation. Transportation Research Record, Vol. 2089, 2008, pp. 101-109.

Wachs, M. Improving efficiency and equity in transportation finance. Brookings Institution, Washington, DC, 2003. 


\section{APPENDIX A}

FARE EQUITY ANALYZER TOOLBOX 


\section{FARE EQUITY ANALYZER TOOLBOX \\ Fare Equity Analyzer Toolbox v2.0 Beta \\ Updated: March 21, 2014}

\section{ABOUT THE FARE EQUITY ANALYZER TOOLBOX}

\subsection{FUNCTIONS}

The Fare Equity Analyzer Toolbox is a Geographic Information System-based decision support toolbox. It enables a transit planner to visualize and compare distance traveled and transit-cost maps for different population profiles and fare structures. This tool estimates costs using a state-of-the-art spatial econometric joint model of trip generation and distance raveled.

\subsection{COMPONENTS}

The Fare Equity Analyzer folder contains the following files and folders:

Toolbox: Fare Equity Analyzer beta 2.0.tbx

Tool 1: Generate Fare Equity Report - One Map

Tool 2: Generate Fare Equity Report - Two Map

Scripts: GenerateOneMapReport.py, GenerateTwoMapReport.py

Templates Folder: GridTemplates.gdb, MapFeatures.gdb, OneMapDifference.mxd, OneMapDistance.mxd, OneMapFare.mxd, OneMapFareDef.mxd, OneMapProfileDef.mxd, OneMapRatio.mxd, OneMapTable.mxd, OneMapTitle.mxd, OneMapTOC.mxd, TwoMapDifference.mxd, TwoMapDistance.mxd, TwoMapFare.mxd, TwoMapFareDef1.mxd, TwoMapFareDef2.mxd, TwoMapFareDefShare.mxd, TwoMapProfile1Def.mxd, TwoMapProfile2Def.mxd, TwoMapRatio.mxd, TwoMapTableShare.mxd, TwoMapTitle.mxd, TwoMapTOC.mxd, difference.lyr, distance.lyr, fare.lyr, ratio.lyr, DescriptiveTable.rlf, DescriptiveTableShare.rlf 


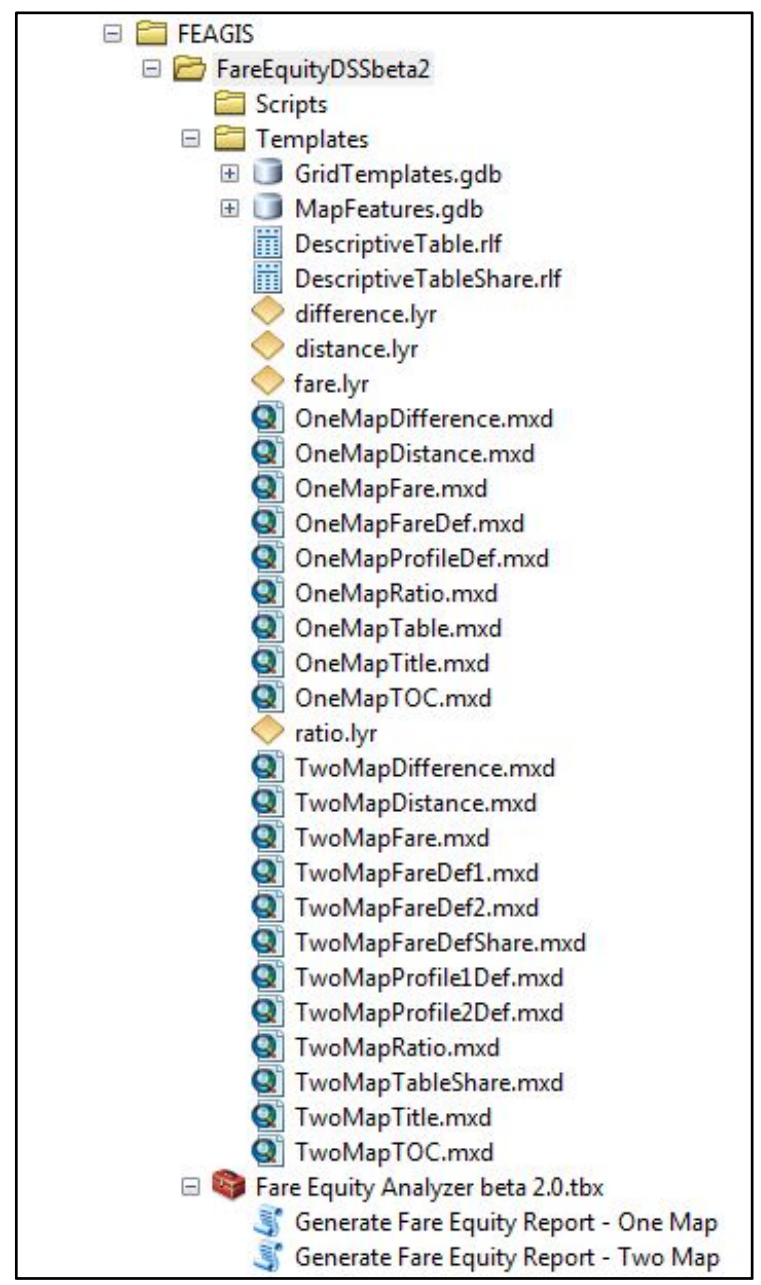

\subsection{SYSTEM REQUIREMENTS}

Currently, this tool has been tested on ArcGIS for Desktop 10.1 and 10.2.1. This tool does not require any other special software except Python (which is typically included with the ArcGIS install). The resources demanded by the tool are limited; so long as the machine has the resources to use ArcGIS, it should be capable of running the tool. Lastly, all data needed for the reports are included in the templates folder, so no internet connection is required.

***Note: While the main folder name can be changed, it is recommended to not change any of the sub-folder names. In addition, any of the files/folders located in the Templates folder should NOT be modified, as that will result in the tool failing to generate the final report. $* * *$ 


\section{HOW TO INSTALL THE FARE EQUITY ANAL YZER TOOLBOX}

Make sure that ESRI ArcGIS for Desktop 10.1 or 10.2 is installed.

Run ArcMap or ArcCatalog.

Click the ArcToolbox icon 圈 on the menu bar to open ArcToolbox.

Right-click on ArcToolbox at the top of the toolbox window, and add the toolbox file - Fare Equity Analyzer beta 2.0.tbx - to ArcToolbox

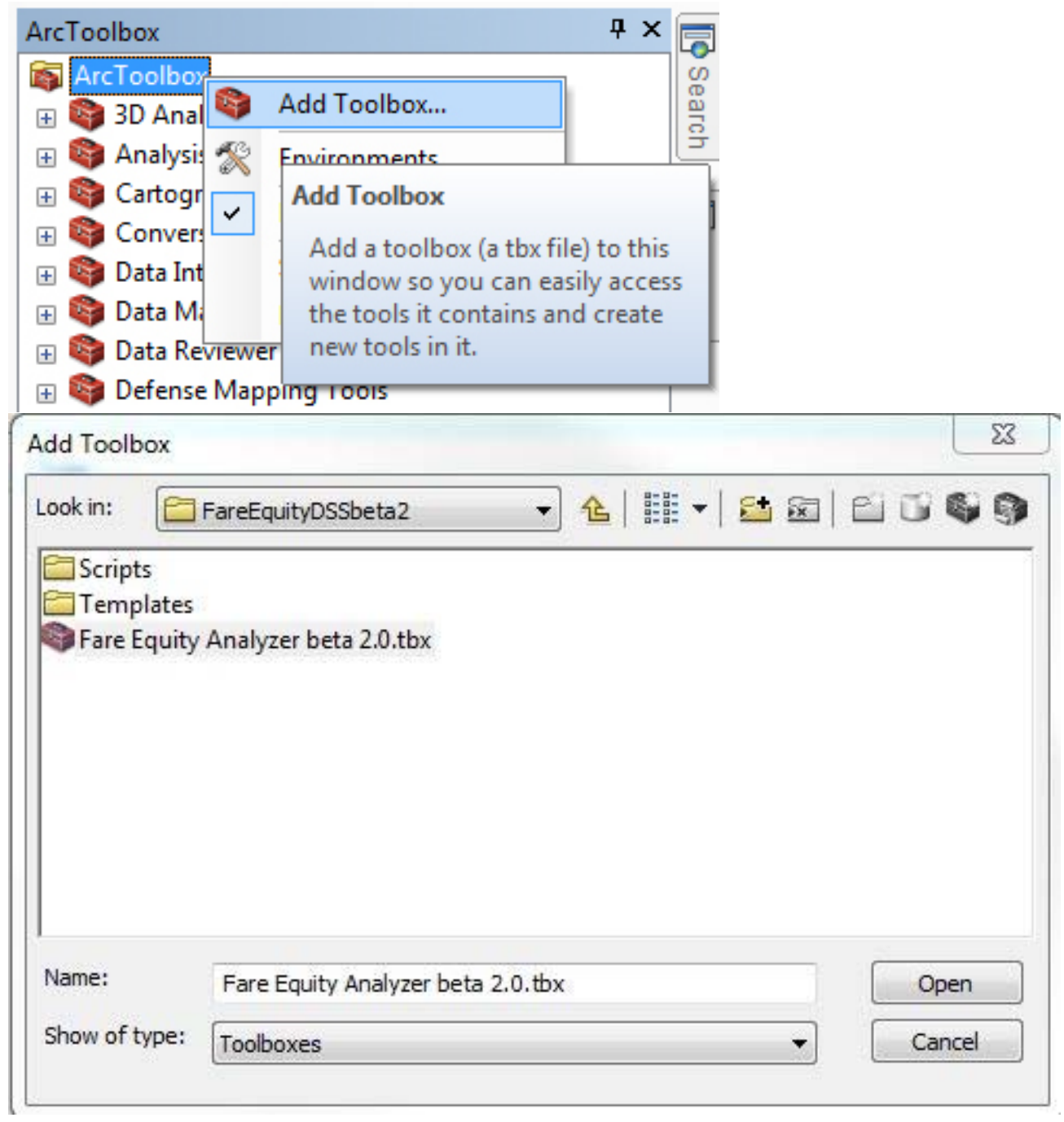




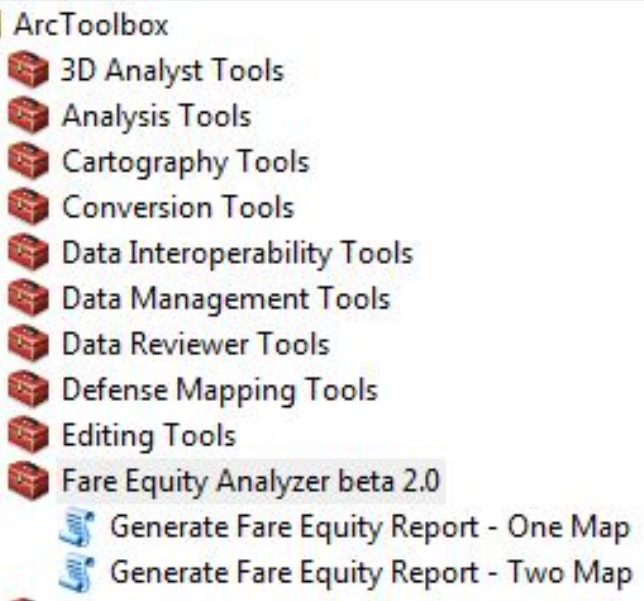

\section{TOOLBOX}

FARE EQUITY ANALYZER TOOLBOX INCLUDES THE FOLLOWING PYTHON SCRIPT TOOLS:

Tool 1: Generate Fare Equity Report - One Map

Tool 2: Generate Fare Equity Report - Two Map

\subsection{TOOL 1: GENERATE FARE EQUITY REPORT - ONE MAP}

Tool 1 Part 1 estimates and creates the following fields on the specified output feature:

Transit trip distance. Expected distance traveled by public transit for the configured socioeconomic profile. Distance estimates are based on the coefficients spatial econometric model calibrated using the 2012 Utah Household Travel Survey.

Distance-based fare. Distance-based fares are commonly structured around a nominal fee per trip plus a distance-based component.

The difference between distance-based fare and flat fare. Calculated using the following formula: (Estimated distance-based fare) - (Estimated flat fare).

The ratio of distance-based fare to flat fare. Calculated using the following formula: (Estimated distance-based fare)/ (Estimated flat fare).

With the results of Tool 1 Part 1, Tool 1 then creates a series of maps of the following fields:

- Transit trip distance

- Distance-based fare

- The difference between distance-based fare and flat fare

- The ratio of distance-based fare to flat fare 
The map layouts and symbology information of the variables are prepared in advance and stored in the templates folder, which includes the layer files (.lyr) and map document files (.mxd).

After the tool is run, all of the MXDs, CSVs, and the final generated report (in PDF format) are stored in the Maps/PDF Output Folder the user selected when running the tool.

\section{Tool 1 Parameters:}

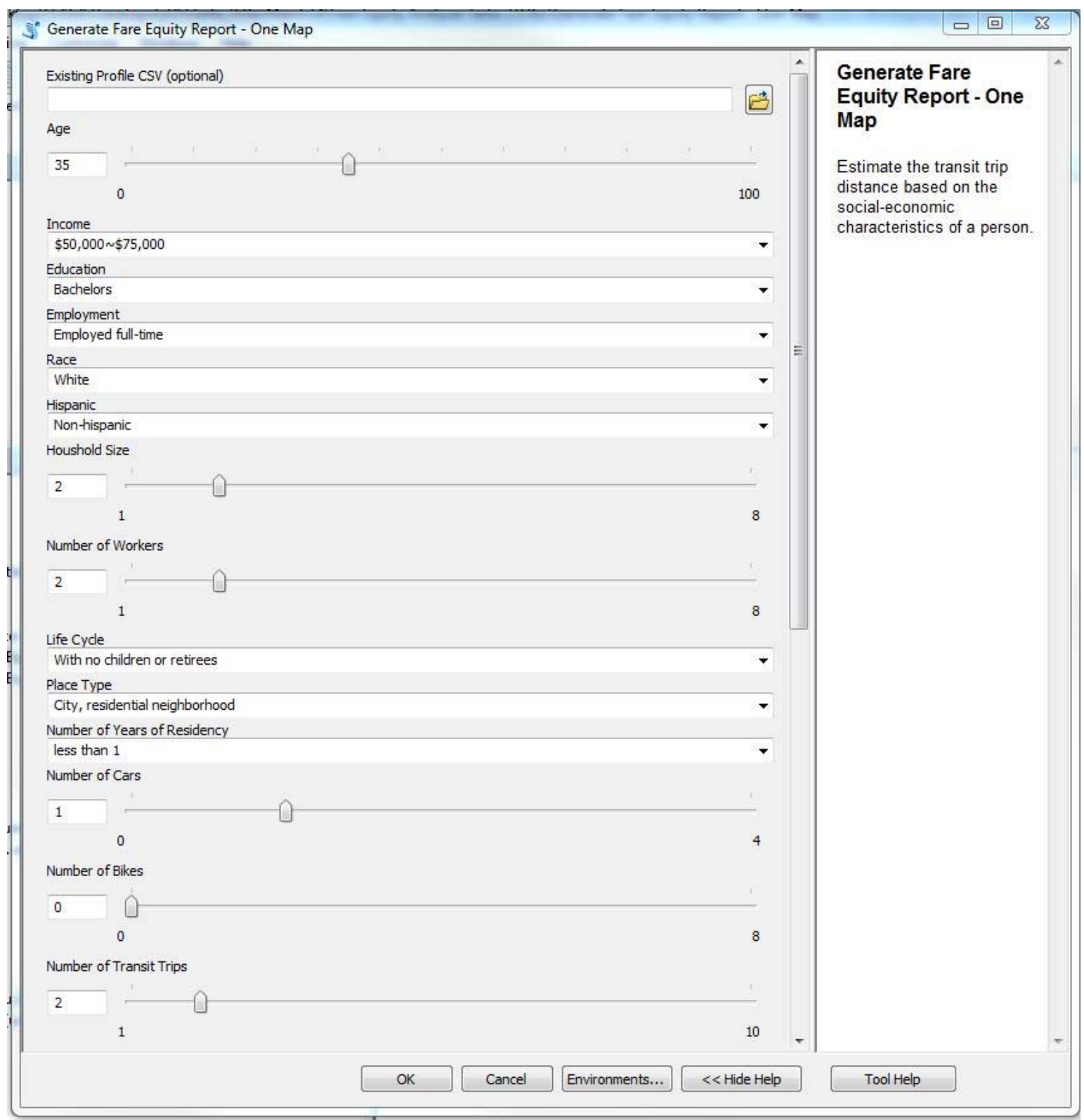




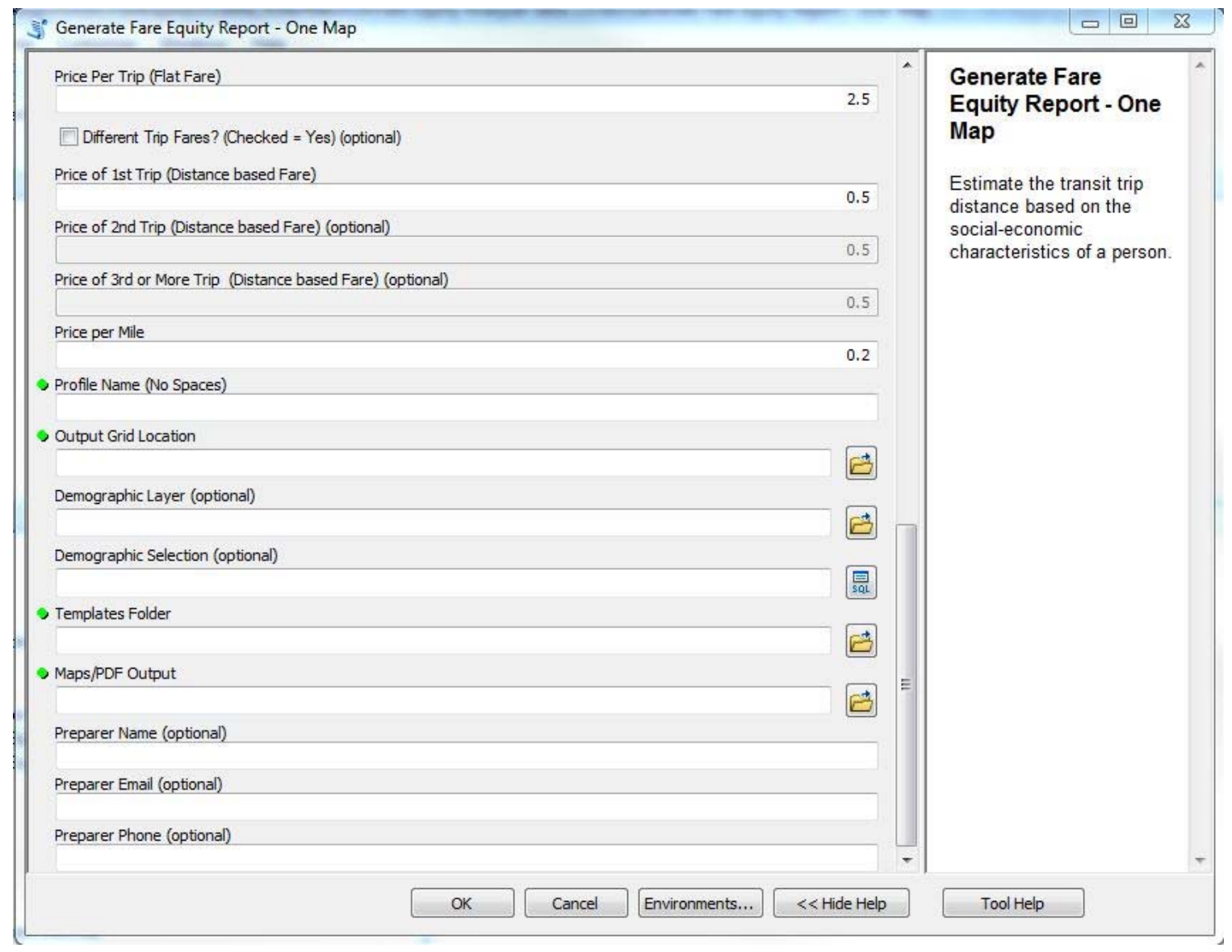

\section{Existing Profile Parameters (optional)}

Whenever a new profile is created, a CSV file is generated named profilename_parameters.cSV. This CSV file contains all of the parameters that were used for that profile. Because the user might want to look at the results for similar profiles with minor changes, the user can select an existing profile's CSV of parameters and they will automatically populate the inputs. The user can then make any changes that they want and rerun the tool with these changes.

\section{Age}

User selects the age of the person of interest. The user can enter a number between 0 and 100 , or use a slider bar.

\section{Income}

User selects the household income level for the person of interest. Options are presented as a drop-down list from which the user selects pre-defined household income ranges. 


\section{Education}

User selects the education level of the person of interest. Options are presented as a drop-

down list from which the user selects pre-defined educational attainment levels.

\section{Employment}

User selects the employment status for the person of interest. Options are presented as a drop-down list from which the user selects pre-defined employment statuses.

\section{Race}

User selects the race of the person of interest. Options are presented as a drop-down list from which the user selects pre-defined racial categories.

\section{Hispanic}

User selects if the person of interest is considered Hispanic or non-Hispanic. These options are presented as a drop-down list from which the user selects pre-defined Hispanic categories.

\section{Household Size}

User selects the number of people in the person of interest's household. The user can manually enter or use the slider bar to select anywhere from one to eight people.

\section{Number of Workers}

User selects the number of workers in the person of interest's household. The user can manually enter or use the slider bar to select anywhere from one to eight workers.

\section{Life Cycle}

User selects the household life cycle of the person of interest (relating to the presence of children or retirees in the household). These options are presented as a drop-down list from which the user selects pre-defined life cycle options.

\section{Place Type}

User selects the type of location that the person of interest lives in. These options are presented as a drop-down list from which the user selects pre-defined location options.

\section{Number of Years of Residency}

User selects the number of years the person of interest has lived at their current residence. The options are presented as a drop-down list of year ranges from which the user selects predefined ranges. 


\section{Number of Cars}

User selects the number of cars that the person of interest's household has. The user can manually enter or use the slider bar to select anywhere from zero to four cars.

\section{Number of Bikes}

User selects the number of bikes that the person of interest's household has. The user can manually enter or use the slider bar to select anywhere from zero to eight bikes.

\section{Number of Transit Trips}

User selects the number of transit trips that the user of interest will take. The user can manually enter or use the slider bar to select anywhere from one to 10 transit trips.

\section{Price Per Trip (Flat Fare)}

User manually enters the flat-fare structure's price per trip to be used for calculations. This input should be in decimal format without commas or dollar signs.

\section{Different Trip Fares - Checkbox}

User checks this box if for the distance-based fare structure, each of the trips will have a separate starting value. If this box is unchecked, all of the trips will assume the starting value of the first trip

\section{Price of First Trip (Distance-based Fare)}

User enters the distance-based fare starting value for the first trip the user of interest will take. This input should be in dollars using decimal format without commas or dollar signs.

\section{Price of Second Trip (Distance-based Fare) (optional)}

If needed, the user enters the distance-based fare starting value for the second trip the user of interest will take. If the checkbox above is unchecked, this input will automatically use the value of the first trip. This input should be in dollars using decimal format without commas or dollar signs.

\section{Price of Third Trip (Distance-based Fare) (optional)}

If needed, the user enters the distance-based fare starting value for the third trip the user of interest will take. If the checkbox above is unchecked, this input will automatically use the value of the first trip. This input should be in dollars using decimal format without commas or dollar signs. 


\section{Price Per Mile}

User enters the price per mile that is added onto the trip starting fare value for the distancebased fare structure. This input should be in dollars using decimal format without commas or dollar signs.

\section{Profile Name (No Spaces)}

The user enters the unique profile name for the particular run of the tool. This profile name is used for many purposes, including being appended to the output files and automatically added to certain parts of the report. Because this name will be used for filenames, no spaces can be used in the name (underscores are acceptable) or else the tool will fail.

\section{Output Grid Location}

The user selects the FILE GEODATABASE that will hold the grid feature that results from running the tool. The file geodatabase must be created using ArcCatalog in advance of using the toolbox.

\section{Demographic Layer (optional)}

The user may select for the resulting output maps in the report to be overlaid by Census tracts of a certain demographic profile. This option allows the user to select the demographic feature (located in the templates folder).

\section{Demographic Selection (optional)}

If the user decided for the demographic layer to be included in the report AND selected the demographic feature layer in the option above, then the user can create an SQL condition to isolate the specific demographic profile of interest.

\section{Templates Folder}

The user selects the templates folder that was provided with the tool. This folder contains all of the required map documents, features, and layer files for the report to be generated successfully.

\section{Maps/PDF Output Folder}

The user selects the FOLDER where the output should be saved. After the tool is run, this location will contain the CSV file of parameters, the MXDs (map files) that the user can change if desired, the PDF report that was generated, and the CSV of the fare comparison table if the user wants to perform calculations with these resulting values.

\section{Preparer Name (optional)}

The user enters the name of the report's preparer. This information is automatically added to the title sheet of the report. Note: This can contain spaces. 


\section{Preparer Email (optional)}

The user enters the email address of the report's preparer. This information is automatically added to the title sheet of the report.

\section{Preparer Phone (optional)}

The user enters the phone number of the report's preparer. This information is automatically added to the title sheet of the report. 


\title{
3.2 TOOL 1: GENERATE FARE EQUITY REPORT - ONE MAP RESULTS
}

\author{
After the tool is run, all of the MXDs, CSVs, and the final generated report (in PDF format) \\ are stored in the Maps/PDF Output Folder the user selected when running the tool. \\ The MXDs that are generated include: \\ OneMapDifference_ProfileName.mxd \\ OneMapDistance_ProfileName.mxd \\ OneMapFare_ProfileName.mxd \\ OneMapRatio_ProfileName.mxd \\ The CSVs that are generated include: \\ ProfileName_Params.csv \\ ProfileName_Table.csv \\ The report that is generated is named: \\ ProfileName_Report.pdf \\ The report includes the following pages: \\ Title Page \\ Table of Contents \\ Profile Definition \\ Fare Definition \\ Distance Traveled Map \\ Distance-based Fare Map \\ Fare Differences: Distance - Flat Map \\ Distance-based Fare / Flat Fare Ratio Map \\ Fare Summary Table
}




\subsection{TOOL 2: GENERATE FARE EQUITY REPORT - TWO MAP}

While tool 1 creates the profile and generates a report with the information about that profile, tool 2 uses two different profiles created using tool 1 to create a report that compares both profiles easily.

The map layouts and symbology information of the variables are also prepared in advance and stored in the templates folder, which includes the layer files (.lyr) and map document files $(. \mathrm{mxd})$.

After the tool is run, all of the MXDs, CSVs, and the final generated report (in PDF format) are stored in the Maps/PDF Output Folder the user selected when running the tool.

\section{Tool 2 Parameters:}

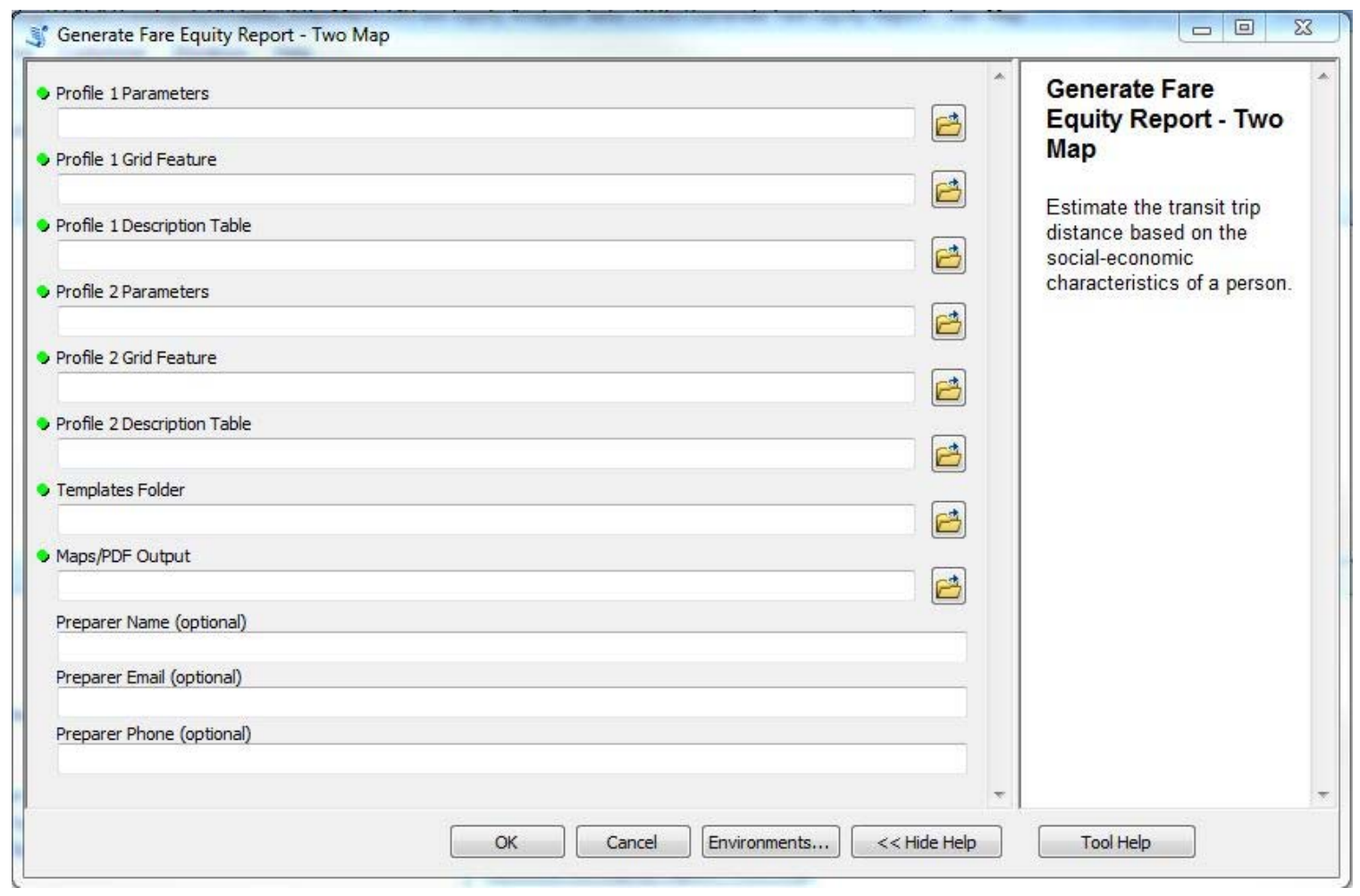

\section{Profile 1 Parameters}

Whenever a new profile is created, a CSV file is generated named profilename_parameters.csv. This CSV file contains all of the parameters that were used for that profile. In order to generate the report that compares two different profiles, the CSV of parameters of each of the profiles needs to be used. This input is where the user selects the first of two profiles to compare. 


\section{Profile 1 Grid Feature}

When the one-map tool was run and the profile was created, so too was a grid feature in the FILE GEODATABASE that the user selected. For this input, the user selects the grid of the profile whose parameters were chosen as profile 1.

\section{Profile 1 Description Table}

When the one-map tool was run and the profile was created, so too was a descriptive table in the FILE GEODATABASE that the user selected. For this input, the user selects the descriptive table of the profile whose parameters were chosen as profile 1 .

\section{Profile 2 Parameters}

This input is where the user selects the second profile's parameters to be used for comparison.

\section{Profile 2 Grid Feature}

When the one-map tool was run and the profile was created, so too was a grid feature in the FILE GEODATABASE that the user selected. For this input, the user selects the grid of the profile whose parameters were chosen as profile 2 .

\section{Profile 2 Description Table}

When the one-map tool was run and the profile was created, so too was a descriptive table in the FILE GEODATABASE that the user selected. For this input, the user selects the descriptive table of the profile whose parameters were chosen as profile 2 .

\section{Templates Folder}

The user selects the templates folder that was provided with the tool. This folder contains all of the required map documents, features, and layer files for the report to be generated successfully.

\section{Maps/PDF Output}

The user selects the FOLDER where the output should be saved. After the tool is run, this location will contain the CSV of parameters, the MXDs that the user can change if desired, the report that was generated, and the CSV of the table if the user wants to perform calculations with these resulting values. 


\section{Preparer Name (optional)}

The user enters the name of the report's preparer. This information is automatically added to the title sheet of the report. Note: This can contain spaces.

\section{Preparer Email (optional)}

The user enters the email address of the report's preparer. This information is automatically added to the title sheet of the report.

\section{Preparer Phone (optional)}

The user enters the phone number of the report's preparer. This information is automatically added to the title sheet of the report.

\subsection{TOOL 2: GENERATE FARE EQUITY REPORT - TWO MAP RESULTS}

After the tool is run, all of the MXDs, CSVs, and the final generated report (in PDF format) are stored in the Maps/PDF Output Folder the user selected when running the tool.

The MXDs that are generated include:

TwoMapDifference_ProfileName1_ProfileName2.mxd

TwoMapDistance_ProfileName1_ProfileName2.mxd

TwoMapFare_ProfileName1_ProfileName2.mxd

TwoMapRatio_ProfileName1_ProfileName2.mxd

The report that is generated is named:

ProfileName1_ProfileName2_Comparison_Report.pdf

The report includes the following pages:

Title Page

Table of Contents

Profile 1 Definition

Profile 2 Definition

Profile 1 / Profile 2 Fare Definition (if fare params. for the profiles were the same)

Profile 1 Fare Definition (if fare params. for the profiles were different)

Profile 2 Fare Definition (if fare params. for the profiles were different)

Distance Traveled Maps

Distance-based Fare Maps

Fare Differences: Distance - Flat Map

Distance-based Fare / Flat Fare Ratio Map 
Fare Summary Table (if fare params. for the profiles were different)

*** For a more in-depth/advanced look at how the tools function, refer to the Appendix *** 


\section{APPENDIX}

The appendix below describes in greater detail how the inputs of each of the tools are used in determining the output.

\subsection{TOOL 1: GENERATE FARE EQUITY REPORT - ONE MAP (ADVANCED)}

\section{Existing Profile Parameters (optional)}

Whenever a new profile is created, a CSV file is generated named profilename_parameters.csv.

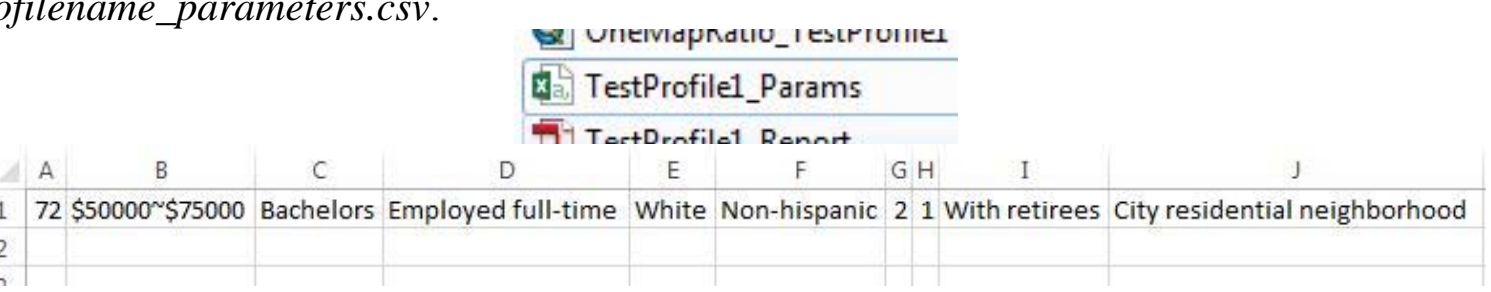

This CSV file contains all of the parameters that were used for that profile. Because the user might want to look at the results for similar profiles with minor changes, the user can select an existing profile's CSV of parameters and they will automatically populate the inputs. The user can then make any changes that they want and then re-run the tool with these changes. This involves the tool's validation program obtaining the values from the CSV and correctly assigning them into the corresponding input fields. The values in the CSV file should not be modified. The tool's validation script should also not be modified.

\section{Age; Income; Education; Employment; Race; Hispanic; Household Size; Number of Workers; Life Cycle; Place Type; Number of Years of Residency; Number of Cars, Number of Bikes; and Number of Transit Trips.}

All of these socio-demographic factors are used as input into the state-of-the-art spatial econometric joint model of trip generation and distance traveled. The results of this model are the various maps that are generated and placed into the PDF report that is created when the tool is run. In addition to being saved in the parameter CSV file, the values of these inputs are also displayed on the Profile Definition page of the report. For more specific information about the model, refer to the research paper that is included with the tool by Dr. Steven Farber.

\section{Price Per Trip (Flat Fare)}

User manually enters the flat fare structure's price per trip to be used for calculations. This input should be in decimal format without commas or dollar signs. Similar to the demographic factors, this fare information is included into a fare model that calculates how much each demographic group spends on transit trips under the flat fare system. 


\section{Different Trip Fares - Checkbox}

The user checks this box for the distance-based fare structure, and each of the trips will have a separate starting value. If this box is unchecked, all of the trips will assume the starting value of trip 1. This input is not used in the actual model, but a logical option. By default, the box is unchecked and only the price of the $1^{\text {st }}$ trip can be entered. The $2^{\text {nd }}$ and $3^{\text {rd }}$ trips are grayed out and the value from trip 1 is automatically updated for the $2^{\text {nd }}$ and $3^{\text {rd }}$ trip. If the user decides that each of the trips will be different, then checking the box allows for the $2^{\text {nd }}$ and $3^{\text {rd }}$ trip inputs to become active and the user can enter different values into all three of the trips.

\begin{tabular}{|lr|}
\hline$\square$ Different Trip Fares? (Checked $=$ Yes) (optional) & \\
Price of 1st Trip (Distance based Fare) & 0.5 \\
\hline Price of 2nd Trip (Distance based Fare) (optional) & 0.5 \\
\hline Price of 3rd or More Trip (Distance based Fare) (optional) & 0.5 \\
\hline \hline Different Trip Fares? (Checked = Yes) (optional) & \\
\hline Price of 1st Trip (Distance based Fare) & 0.75 \\
\hline Price of 2nd Trip (Distance based Fare) (optional) & 0.5 \\
\hline Price of 3rd or More Trip (Distance based Fare) (optional) & 0.25 \\
\hline
\end{tabular}

Price Per Trip (Flat Fare); Price of $1^{\text {st }}$ Trip (Distance-based Fare); Price of $2^{\text {nd }}$ Trip (Distance-based Fare) (optional); Price of $3^{\text {rd }}$ Trip (Distance-based Fare) (optional); and Price Per Mile.

All of these fare factors are used as input into determining how the different demographic groups were affected by the change from the flat-fare structure to the distance-based fare structure. The results using these factors are shown in the table that is generated and placed into the PDF report that is created when the tool is run. In addition to being saved in the parameter CSV file, the values of these inputs are also displayed on the Fare Definition page of the report.

\section{Profile Name (No Spaces)}

The user enters the unique profile name for the particular run of the tool. This profile name is used for many purposes, including being appended to the output files. Because this name will be used for filenames, no spaces can be used in the name (underscores are acceptable) or else the tool will fail. The profile name is also automatically added to certain parts of the report. This includes the title page, distance-traveled map, distance-based fare map, fare difference, distance-flat map, and the distance-based fare / flat fare map. 


\section{Output Grid Location}

The user selects the FILE GEODATABASE that will hold the grid feature that results from running the tool. The file geodatabase must be created using ArcCatalog in advance of using the toolbox. Tool 2 requires that the input be feature classes, so the grids must be saved into a FILE GEODATABASE for this to happen.

\section{Demographic Layer (optional)}

The user may select for the resulting output maps in the report to be overlaid by Census tracts of a certain demographic profile. This option allows the user to select the demographic feature (located in the templates folder).

\section{Demographic Selection (optional)}

If the user decided for the demographic layer to be included in the report AND selected the demographic feature layer in the option above, then the user can create an SQL condition to isolate the specific demographic profile of interest.

\section{Templates Folder}

The user selects the templates folder that was provided with the tool. This folder contains all of the required map documents, features, and layer files for the report to be generated successfully. The template folder also contains the "holder" feature classes for the map documents. These "holder" feature classes are replaced by the feature classes that are generated by the tool.

\section{Maps/PDF Output Folder}

The user selects the FOLDER where the output should be saved. After the tool is run, this location will contain the CSV file of parameters, the MXDs (map files) that the user can change if desired, the PDF report that was generated, and the CSV of the fare comparison table if the user wants to perform calculations with these resulting values.

\section{Preparer Name (optional)}

The user enters the name of the report's preparer. This information is automatically added to the title sheet of the report. Note: This can contain spaces. 


\section{Preparer Email (optional)}

The user enters the email address of the report's preparer. This information is automatically added to the title sheet of the report.

\section{Preparer Phone (optional)}

The user enters the phone number of the report's preparer. This information is automatically added to the title sheet of the report. 


\subsection{TOOL 2: GENERATE FARE EQUITY REPORT - TWO MAP (ADVANCED)}

\section{Profile 1 Parameters}

Whenever a new profile is created, a CSV file is generated named profilename_parameters.csv. This CSV file contains all of the parameters that were used for that profile. In order to generate the report that compares two different profiles, the CSV of parameters of each of the profiles needs to be used. This input is where the user selects the first of two profiles to compare. The main purpose of inserting these parameters is so that the profile 1 demographic and fare definition pages of the report can be populated with the correct information.

\section{Profile 1 Grid Feature}

When the one-map tool was run and the profile was created, so too was a grid feature in the FILE GEODATABASE that the user selected. For this input, the user selects the grid of the profile whose parameters were chosen as profile 1 . The grid feature contains all of the demographic results that were created based on the input parameters when the profile was created in tool 1 . This grid feature and the resulting attributes are used for the different maps that are shown in the report.

\section{Profile 1 Description Table}

When the one-map tool was run and the profile was created, so too was a descriptive table in the FILE GEODATABASE that the user selected. For this input, the user selects the descriptive table of the profile whose parameters were chosen as profile 1 . The description table contains all of the fare results for each demographic group that were created based on the fare input parameters when the profile was created in tool 1. This description table and the resulting attributes are used to populate the fare summary table that is appended to the end of the report (only if both profiles have different fare definitions).

\section{Profile 2 Parameters}

This input is where the user selects the second profile to compare. The main purpose of inserting these parameters is so that the profile 2 demographic and fare definition pages of the report can be populated with the correct information.

\section{Profile 2 Grid Feature}

When the one-map tool was run and the profile was created, so too was a grid feature in the FILE GEODATABASE that the user selected. For this input, the user selects the grid of the profile whose parameters were chosen as profile 2 . The grid feature contains all of the demographic results that were created based on the input parameters when the profile was created in tool 1. This grid feature and the resulting attributes are used for the different maps that are shown in the report. 


\section{Profile 2 Description Table}

When the one-map tool was run and the profile was created, so too was a descriptive table in the FILE GEODATABASE that the user selected. For this input, the user selects the descriptive table of the profile whose parameters were chosen as profile 2 . The description table contains all of the fare results for each demographic group that were created based on the fare input parameters when the profile was created in tool 1. This description table and the resulting attributes are used to populate the fare summary table that is appended to the end of the report (only if both profiles have different fare definitions).

\section{Templates Folder}

The user selects the templates folder that was provided with the tool. This folder contains all of the required map documents, features, and layer files for the report to be generated successfully. The template folder also contains the "holder" feature classes for the map documents. These "holder" feature classes are replaced by the feature classes that are generated by the tool.

\section{Maps/PDF Output Folder}

The user selects the FOLDER where the output should be saved. After the tool is run, this location will contain the CSV file of parameters, the MXDs (map files) that the user can change if desired, the PDF report that was generated, and the CSV of the fare comparison table if the user wants to perform calculations with these resulting values.

\section{Preparer Name (optional)}

The user enters the name of the report's preparer. This information is automatically added to the title sheet of the report. Note: This can contain spaces.

\section{Preparer Email (optional)}

The user enters the email address of the report's preparer. This information is automatically added to the title sheet of the report.

\section{Preparer Phone (optional)}

The user enters the phone number of the report's preparer. This information is automatically added to the title sheet of the report. 